\title{
Article \\ Determination of Methodology and Research of the Influence of the Trial Run of High-Precision Reducers on the Change of Their Characterizing Properties
}

\author{
Marek Kočiško ${ }^{1, *}$, Martin Pollák ${ }^{1}\left(\mathbb{D}\right.$, Monika Töröková $^{1}$, Petr Baron ${ }^{1} \mathbb{D}$, Dušan Paulišin ${ }^{2}$ and Juraj Kundrík ${ }^{1}$ \\ 1 Faculty of Manufacturing Technologies with a Seat in Presov, Technical University of Kosice, Bayerova 1, \\ 08001 Presov, Slovakia; martin.pollak@tuke.sk (M.P.); monika.torokova@tuke.sk (M.T.); \\ petr.baron@tuke.sk (P.B.); juraj.kundrik@tuke.sk (J.K.) \\ 2 Spinea Technologies Ltd., Volgogradska 13, 08001 Presov, Slovakia; dusan.paulisin@gmail.com \\ * Correspondence: marek.kocisko@tuke.sk; Tel.: +421-55-602-6354
}

check for

updates

Citation: Kočiško, M.; Pollák, M.; Töröková, M.; Baron, P.; Paulišin, D.; Kundrík, J. Determination of Methodology and Research of the Influence of the Trial Run of High-Precision Reducers on the Change of Their Characterizing Properties. Appl. Sci. 2021, 11, 3859. https://doi.org/10.3390/app11093859

Academic Editor: Daniel A. Vera

Received: 15 March 2021

Accepted: 20 April 2021

Published: 24 April 2021

Publisher's Note: MDPI stays neutral with regard to jurisdictional claims in published maps and institutional affiliations.

Copyright: (c) 2021 by the authors. Licensee MDPI, Basel, Switzerland. This article is an open access article distributed under the terms and conditions of the Creative Commons Attribution (CC BY) license (https:// creativecommons.org/licenses/by/ $4.0 /)$

\begin{abstract}
This paper describes, in detail, the research of the influence of the trial run of high-precision reducers on the change of their characterizing parameters with the subsequent determination of the methodology for the identification of their critical parameters and positioning accuracy. The research was carried out on a sample of high-precision reducers during a $48 \mathrm{~h}$ run-in with the evaluation of changes in their characterizing parameters. The developed methodology unifies the approach to measuring the static and dynamic properties of high-precision reducers to identify their critical parameters and positioning accuracy. The article also points to the need for the correct implementation of the process for the introduction of the bearing reducer into operation after its incorporation into the relevant equipment with emphasis on improving the monitored critical parameters. The running-in of reducers is a little-explored area in terms of its effect on changing the wide range of characterizing properties of high-precision reducers. At the same time, it is complicated by the non-existent uniform methodology for the implementation of their run-in.
\end{abstract}

Keywords: high precision reducer; trial run of bearing reducer; repeated accuracy measurement; cycloid gearbox

\section{Introduction}

Technologically advanced devices place increased demands on precise and reliable positioning in industrial applications, especially in robotics and high-precision machines. These requirements lead to the increased use of high-precision cycloidal and harmonic propulsion systems. The reducer, as part of the actuator drive unit, significantly influences its properties (the properties of the entire propulsion system). Reducers used in robotic joints are the most complex subsystems of robots [1-3].

Recently, these cycloidal, harmonic and planetary reducers have been brought to perfection to ensure that the robotic system has the properties required. In addition to the requirements for accuracy and reliability, a high gear ratio, high kinematic accuracy, high tilting rigidity, backlash-free operation, high torque capacity, compact size, low weight and high load capacity are also expected [4].

High-precision gear mechanisms (reducers) are used in combination with actuators and form a mechatronic node. The mechatronic node can be described as a coupling member between the non-power (information) control part, and the power control part of the system. Energy conversion occurs in the power section. The mechatronic node can be understood as a complex system consisting of a servomotor, a reducer, a feedback sensor and possibly also a brake or a redundant position sensor. Such a device of precision mechanics, in combination with control electronics, enables precise control of the position, speed, simplification of kinematic structures and increase in dynamics while reducing the demands on the assembly of individual sub nodes [5-7]. 
Typical for today is highly automated and flexible production aligned with the principles of Industry 4.0. Progressive automation is a fundamental pillar of the modern production process, which requires accuracy, repeatability and minimal deviations. These factors are a prerequisite for efficient operation. An overview of high-precision reducers for industrial robots that operate in accordance with the principles of Industry 4.0 is given in the paper by the team of authors of Pham A.D. et al. [8]. Many research institutes and development centers work on the continuous development and innovation of highprecision reducers. The new design proposal is addressed by authors of several studies, an example being the paper of Blagojevic M. et al. [9], or the paper by Litvin F.L. et al. [10]. In their study, Mao H. et al. [11] present an innovative cycloidal planetary reducer, utilizing the principle of internal engagement instead of an external one between the cycloidal wheel and the pins of the traditional reduction wheel. Its results prove that the proposed transmission power of the reducer is competitive compared to traditional RV reducers. Prototype testing is performed, parameters in individual phases of product life are analyzed, and stress tests are conducted. In their paper, Sun X. et al. [12] focus on the analysis of a new method of modifying the parabolic profile to improve the transmission accuracy, where the result was a difference of up to $5 \%$ between the errors measured and the results calculated, thus proving the correctness of this system. The engagement stiffness of the bevel gears in the transmission of the rotational bevel vector was described in the study by Huang Y. et al. [13], which helps researchers to better understand the influence of various parameters on the analysis of the dynamic characteristics of transmission systems. In their paper, the authors of Pham A.D. et al. focused on the analysis of the efficiency of cycloidal reducers with tolerance achieved by means of an approximate force distribution of an ideal cycloidal reducer [14]. The experimental work was carried out by a team of authors (Terakawa T. et al.) in order to clarify the optimal input formula for precise rotation using a prototype of a motor designed by them [15]. In their publication, a team of authors (Gorla C. et al.) addressed the theoretical model, focusing on its fine tuning with the goal of predicting the behavior of the cycloid unit in operation and improving the procedure of designing this unit [16]. In their paper, Yamada S. et al. [17] proposes a precise method of joint torque control with backlash compensation using information on the code on the side of the load application. The efficient use of encoder information on the side of the load application allows the proposed method to compensate for the rapid backlash effect.

Based on the experimental analyses, the new backlash compensation model is proposed to solve the problems caused by the conventional backlash compensation model. In their study, the team of Shih Y.P. et al. [18] deal with the design of the accurate evaluation of cycloidal devices. The research focuses on the creation of a mathematical model of cycloidal equipment in which the areas of profile errors and cog thickness, spacing and jerking errors are tested. The profile points, measured by the coordinate measuring device, are divided into groups of cogs and then formulated as curves using the B-spline curve technique. Currently, the aim of much research is to significantly support the enhancement of their own development base, which ensures innovation and new product development.

To a large extent, the expectations of the current industry from drive units is that the transmission of force effects be done with higher kinematic accuracy. The main part of such a unit is the reducer, generally referred to as a transmission mechanism, whose main function is the transformation of power quantities. They are designed to reduce the speed of the driving machine to the input speed of the driven machine at a constant transmission.

High-precision reducers are based on several mechanical transmission principles:

- Planetary mechanism-reducers with involute gearing.

- Cycloidal mechanism - reducers with trochoidal gearing.

- Harmonic mechanism-reducers with involute gearing.

The manufacturers listed below belong to the world's leading manufacturers of highprecision reducers used in robotics and equipment requiring high-precision motion, each of which produces the following patented reducers: 
- Spinea-Slovak manufacturer of high-precision compact bearing reducers TwinSpin. Their global market share is about 3.3\%.

- Nabtesco-Japanese manufacturer of high precision reducers. Their share of the precision compact reducers market is $47 \%$.

- Sumitomo Cyklo-Japanese manufacturer of precision reducers. Their global market share for precision gearboxes is $11.7 \%$.

- Harmonic Drive-Japanese manufacturer of precision reducers. This company uses harmonic transmission in their gearboxes. Their share of the precision compact reducers market is $37.5 \%$.

- Other manufacturers of precision gearboxes with various transformer members share about $0.5 \%$ of the world market [19].

The paper delves into the research of the influence of the trial run of high-precision reducers on the change in their characterizing properties. As there is no exact trial run methodology for high-precision reducers, only individual manufacturers' recommendations, the research is focused on the influence of their short-term trial run of $48 \mathrm{~h}$ on the change in the important individual parameters.

\section{Parameters Characteristic of High-Precision Reducers}

The characteristics of high-precision reducers are backlash, dead zone, hysteresis, angular transmission error, high torque capacity, high torsional and tipping rigidity, high efficiency, long life, and small size and weight. Many authors and research teams from all over the world deal with the issue of researching the characteristic properties of highprecision reducers. The issue of backlash is elaborated in more detail in many publications of authors such as Xiong Y. et al. [20], Margielewicz J. et al. [21], as well as in the study by the authors of Getachew A.A. et al. [22] dedicated to monitoring the effect of backlash on transmission error and time-varying mesh stiffness. The simulation and analysis of the exact operation of robots and gear tooth contact were discussed by the authors Spitas C. et al. [23] and Walha L. et al. [24] in their publications. Angular measurements of high-precision reducers used in robots have been investigated by Xue J. et al. [25]. Many mathematical tools are used to process calculations and model control systems, which were discussed in the publication by Caldarola F. et al. [26]. The nonlinearity of the behavior of transmission systems and their analysis was discussed in more detail by authors Farshidianfar A. et al. [27].

\subsection{Backlash (Backlash in Teeth)}

The term backlash is defined as the backlash between adjacent mechanical parts of the transmission gears, or as the value by which the width of the space transcends the tooth on the pitch circle. The backlash has a negative effect on the precise control of actuators containing a gear mechanism, the properties of which are important parameters with respect to the use of actuators or higher nodes.

A generally acceptable model of static backlash in the teeth represents the backlash in the teeth, where $\mathrm{v}$ is the output, $u$ is the input, $m$ represents the incline and $\alpha>0$ is half the width of the gap representing the backlash in the teeth. In gearboxes, the width of the gap means the total width or the gap between the co-engaging gears of the gearbox. The model of Figure 1 is simplified, since in the actual gearbox the initial position of the teeth does not lie in the middle [28]. 


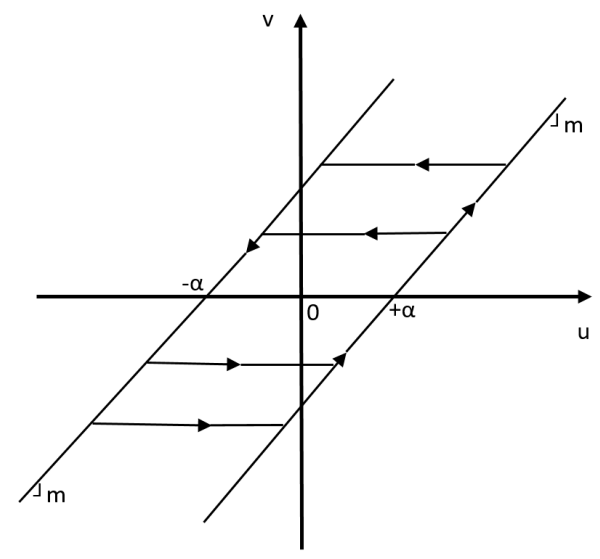

Figure 1. Backlash in the teeth model.

The static backlash in the teeth is represented by two parallel lines-one ascending and one descending, connected by a horizontal line, representing the backlash in the teeth itself.

The ascending line is active if the input $v(t)$ and the output $u(t)$ grow, i.e.,

$$
u(t)=m(v(t)+\alpha), \text { if }: m>0, \dot{v}(t)>0
$$

The descending line is active if $v(t)$ and the $u(t)$ simultaneously fall, i.e.,

$$
u(t)=m(v(t)-\alpha) \text {, where }: \dot{v}(t)<0
$$

If the tooth of the gear is located in the gap between the two teeth of the engaging wheel, then the following holds: $\dot{u}(t)=0$.

Mathematical representation of the backlash in the teeth:

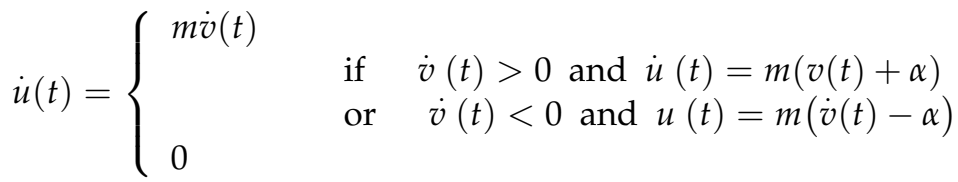

\subsection{Hysteresis}

The static backlash in the teeth is represented by two parallel lines-one ascending and one descending, connected by a horizontal line, representing the backlash in the teeth itself.

Hysteresis is one of the basic features of gearboxes. This characteristic conveys information about the static, as well as dynamic, properties of the examined gearbox. The basic and, at the same time, the most important characteristics that can be obtained from the hysteresis curve on the gearbox subjected to the measurement include torsional rigidity, backlash in the teeth and positioning accuracy. "If the input shaft and the body are secured against rotation and the torque acts on the output flange, the graphical representation of the load has the shape of a hysteresis curve." Thus, hysteresis is an undesirable factor that contributes to faster wear (Figure 2).

In general, the hysteresis curve is an undesirable factor, adversely affecting positioning accuracy and wear. The hysteresis curve of the gearbox can be considered a quasi-static property of the gearbox, as it is measured; therefore, it is not possible to compensate for this property while the gearbox is running. 


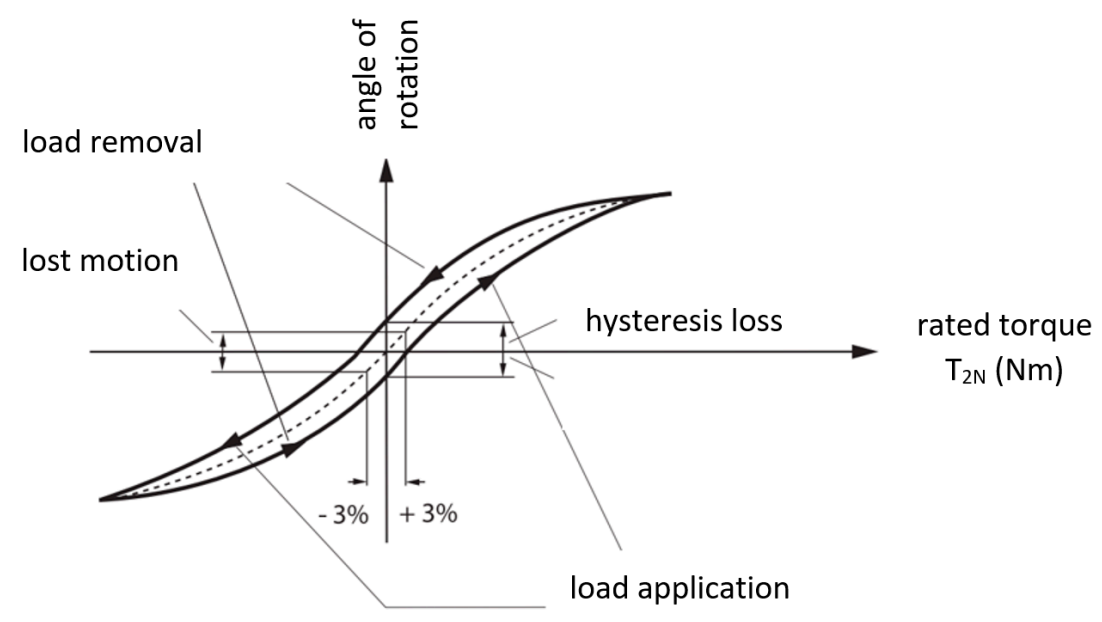

Figure 2. Hysteresis curve typical for Sumitomo Fine Cyclo/Spinea TwinSpin.

The hysteresis curve of the gearbox is a variable nonlinearity, which depends on the position of rotation of the output flange, whose hysteresis curve is to be measured, and on the load moment acting on the reducer. Different changes in the hysteresis characteristic of the same gearbox emerge when the hysteresis curve is measured in several positions of the output position. The difference is due to imperfect production and assembly despite the high precision of the production equipment, and also as a result of the pairing system of individual components of which the gear unit is composed. This fact points to the uniqueness of each gearbox, which, despite the same production technology and the effort to approach the ideal parameters of the individual components, has its own unique properties.

\subsection{Angular Transmission Error}

The angular transmission error (ATE) is the sum of the maximum positive and negative differences between the theoretical and actual rotation angle of the rotary module output. It represents the error between the input angle of the shaft rotation and the output angle of the flange rotation of the rotary module. Knowing this characteristic of the rotary module (in various connection designs) is especially important for the uniformity, smoothness, accuracy and repeatability of the output position.

As Xu H. et al. [29] write in their paper, the transmission error is generally measured under the conditions of zero load and low speed. However, low speed is a general concept and there is no general standard of speed measurement or proper scientific grounds for its definition. Therefore, it is difficult to obtain consistent transmission accuracy evaluation results for the same reducer.

ATE is measured at a constant velocity and a very small angular speed without any load to eliminate the hysteresis effect of fast dynamic events. The actual velocity of the output position depends on the input position of the inlet flange and the ATE value in this position [30].

This dependence can be described as follows:

$$
\omega_{\text {out }\left(\varphi_{\text {in }}\right)}=i_{\left(\varphi_{\text {in }}\right)} \cdot \omega_{\text {in }}=\left(i_{\text {th }}+\Delta i_{\left(\varphi_{\text {in }}\right)}\right) \cdot \omega_{\text {in }}
$$

By integrating this equation, we get a change in the output position depending on the ATE:

$$
\Delta \varphi_{c h\left(\varphi_{i n}\right)}=\int \Delta \omega_{\text {out }} d t=\int \Delta i_{\left(\varphi_{i n}\right)} \cdot \omega_{i n} d t=\omega_{\text {in }} \int \Delta i_{\left(\varphi_{i n}\right)} d t
$$

ATE $\Delta i$ can also be expressed using the harmonic function:

$$
\Delta i_{\left(\varphi_{i n}\right)}=\sum_{k} \Delta i_{k} \cdot \sin \left(\frac{2 \pi}{T_{k}} \varphi_{i n}+\gamma_{k}\right), \quad k>0
$$


where $T_{k}$ is the length of the period on the side of the drive $\varphi_{i n}$ is the angle of rotation of the transmission input flange.

By adding Equation (6) into Equation (5), the following derivation $\Delta \varphi_{c h}\left(\varphi_{i n}\right)$ is obtained:

$$
\Delta \varphi_{c h\left(\varphi_{i n}\right)}=\omega_{i n} \sum_{k} \Delta i_{k} \cdot \int \sin \left(\frac{2 \pi}{T_{k}} \varphi_{i n}+\gamma_{k}\right) d t
$$

where, given the constant speed when measuring ATE,

$$
\Delta \varphi_{c h\left(\varphi_{i n}\right)}=\omega_{i n} \sum_{k} \Delta i_{k} \cdot \int \sin \left(\frac{2 \pi}{T_{k}} \varphi_{i n}+\gamma_{k}\right) d t=\sum_{k} \frac{T_{k} \cdot \Delta i_{k}}{2 \pi} \cos \left(\frac{2 \pi}{T_{k}} \varphi_{i n}+\right) \gamma_{k}
$$

\subsection{Dead Zone}

The dead zone is measured similarly to ATE $\Delta \varphi_{c h}$. The difference is that during the entire measuring range, the positive, as well as the negative, direction of rotation is measured at the same time and not separately, as is the case with ATE. The dead zone represents the difference of the following deviations in the same position of the output flange rotation:

$$
\Delta \varphi_{m c h}=\Delta \varphi_{c h}^{-}-\Delta \varphi_{c h}^{+}
$$

It should be noted that each manufacturer has its own terminology, which differs in the individual descriptions of the same quantities, e.g., Backlash, Lost Motion (LM), and Dead Zone. Many times, this quantity is also referred to as the gearbox backlash, and such a designation is a bit confusing with respect to precision gearboxes with quasi-zero backlash. In case of the TwinSpin Spinea gearboxes, the dead zone is called based on the hysteresis characteristic as follows:

The dead zone (DZ) is the angle of rotation of the output flange at $\pm 3 \%$ of the nominal torque measured at the center of the hysteresis curve (Figure 3). If the input shaft and the body are secured against rotation and the torque acts on the output flange, DZ can be measured under such conditions 0 .

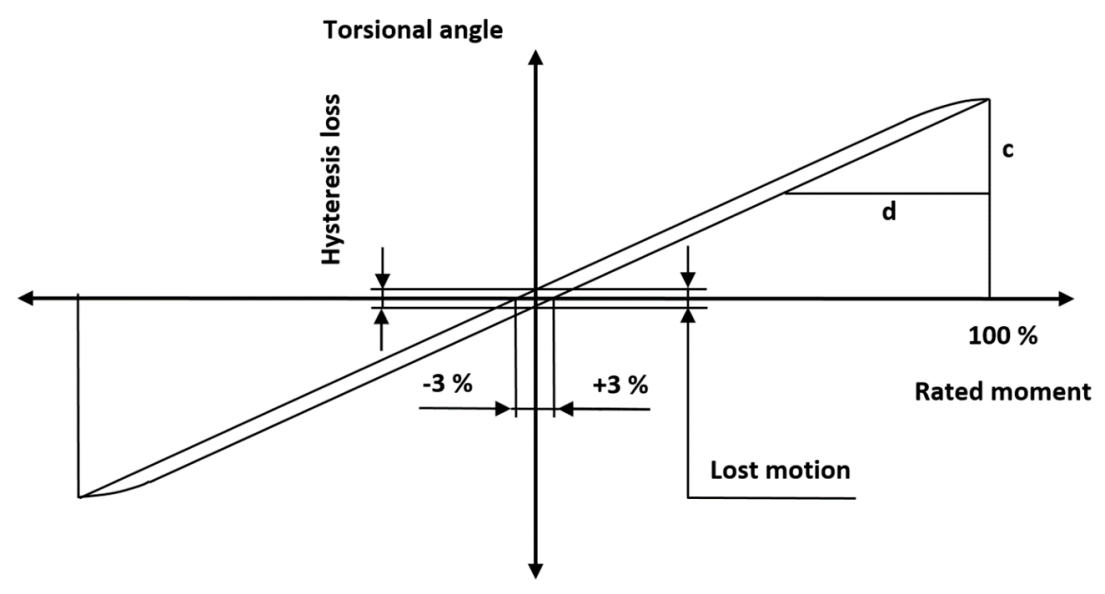

Figure 3. Dead zone definition based on the hysteresis curve.

The definition of torsional rigidity is based on this characteristic, defined by the following relation:

$$
k_{t}=\frac{c}{d}[\mathrm{Nm} / \operatorname{arcmin}]
$$

\subsection{Other Parameters Characteristic of High-Precision Reducers}

- Starting torque-a load-free, quasi-static torque is required to start the rotation of the input shaft if no load is applied to the output flange.

- Reverse torque- the torque applied to the output flange that is required to start the rotation of the input shaft, to which no load is applied. 
- Tipping rigidity—high-precision gearboxes transmit external forces and torque loads using integrated output bearings. When the load is applied to the output flange, the angle of deflection of the flange is proportional to the respective tilting torque. The torque rigidity $\mathrm{Mt}$ is the tipping torque at which the output flange deviates by an angle of $\Theta=1^{\prime}$.

- Effective input speed - the limit value of the average speed of the working cycle.

- Maximum continuous input speed - the speed limit value in continuous operating mode, $\mathrm{S} 1$.

- Maximum acceleration and braking torque-due to the inertial load, the torque acting during acceleration and braking is higher than the nominal value.

\section{Description of the Investigated Problem}

The primary diagnostics of the trial run impact will focus on Spinea, the Slovak manufacturer of cycloidal bearing reducers, TwinSpin. It is necessary to point out the design of the TwinSpin bearing reducer, which integrates roller bearings in the radial and axial arrangement of the rolling elements. By implementing assembled roller bearings, space savings are achieved under a controlled maximum carrying capacity. The TS 050 semi-hollow bearing reducer (BR) was chosen as the basic representative for diagnostics purposes (Table 1).

Table 1. Conditions of measurements applied to TS 050.

\begin{tabular}{ccc}
\hline & TS 050 & \\
\hline Gear ratio & i & 63 \\
Nominal output torque $100 \%$ & TR $100 \%[\mathrm{Nm}]$ & 18 \\
Nominal output torque $50 \%$ & TR $50 \%[\mathrm{Nm}]$ & 9 \\
Rated output speed & $\mathrm{nR}[\mathrm{rpm}]$ & 1000 \\
Vibration measurement & - & Yes \\
Lubricant analysis & - & Yes \\
Amount of lubricant & {$\left[\mathrm{cm}^{3}\right]$} & 2.85 \\
Lubricant type & & Castrol Tribol TT1 PD \\
\hline
\end{tabular}

The measurement was done on a diagnostic device, which allows the measurement to be performed in two required configurations, as follows.

\subsection{Measurement of BR Characteristics-Configuration A}

The measured bearing reducer (BR) is driven by a servomotor from the side of the BR input flange and a mechanical weight (load) is applied onto its arm on the BR side of the output flange (Figure 4). A bellows coupling was used to compensate for the angular misalignments, radial misalignments and axial misalignments of the connected shafts, as well as to ensure accurate transmission of angular motion and torque. Figure 5 shows a realistic view of the measuring stand. 


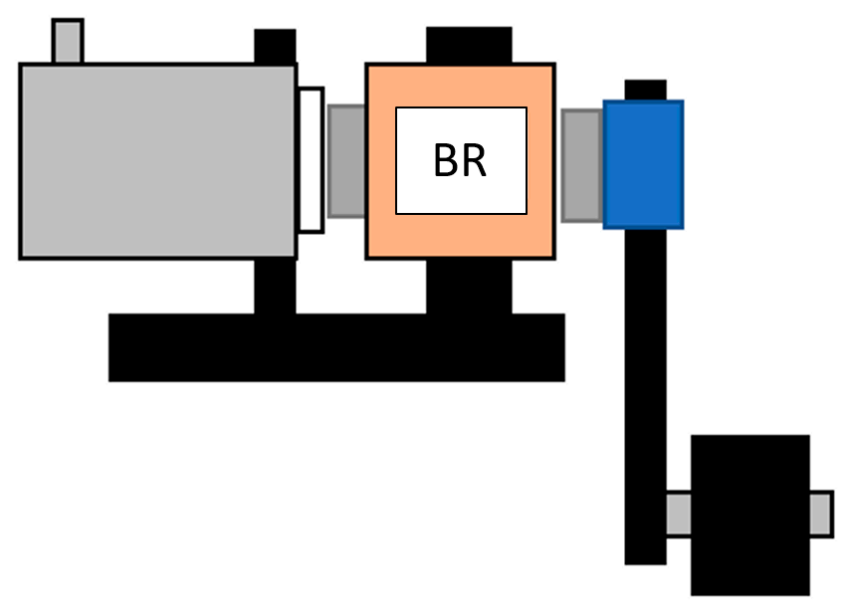

Figure 4. BR connection arrangement in configuration A.

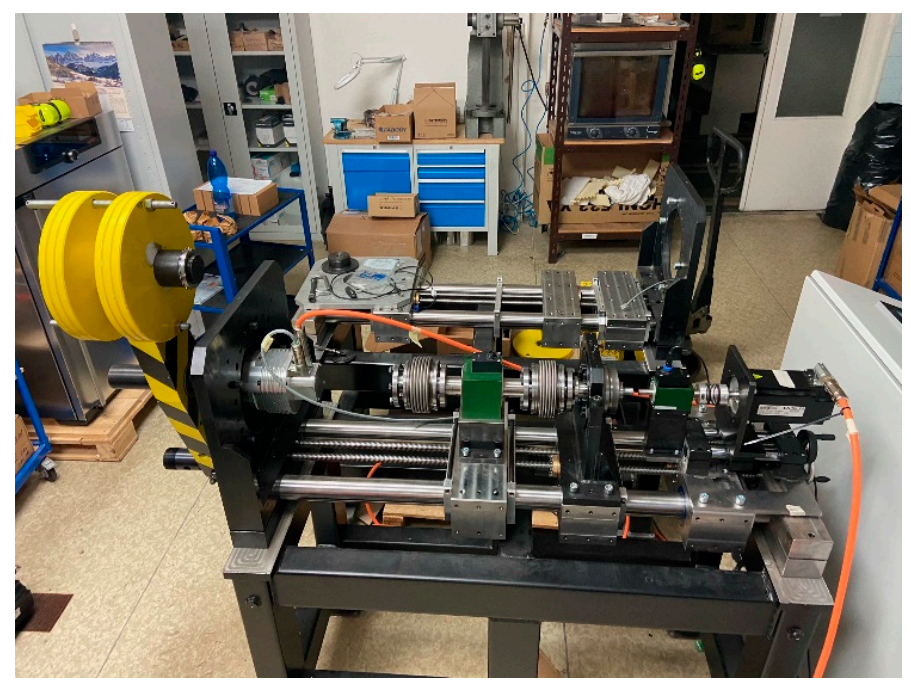

Figure 5. View of the stand in configuration A.

\subsection{Measurement of BR Characteristics-Configuration B}

The bearing reducer (BR) subjected to measurement is located on a common axis with the driven and loading servomotor (Figure 6). The loading drive forms a connection between the planetary reduction mechanism and the loading servomotor. In this configuration, the measuring set includes an external position sensor and an external torque sensor. A bellows coupling was used to compensate for the angular misalignments, radial misalignments and axial misalignments of the connected shafts, as well as to ensure accurate transmission of angular motion and torque. Figure 7 shows a realistic view of the measuring stand.

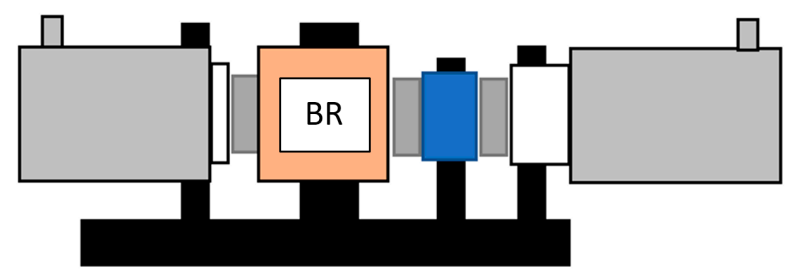

Figure 6. BR connection arrangement in configuration B. 


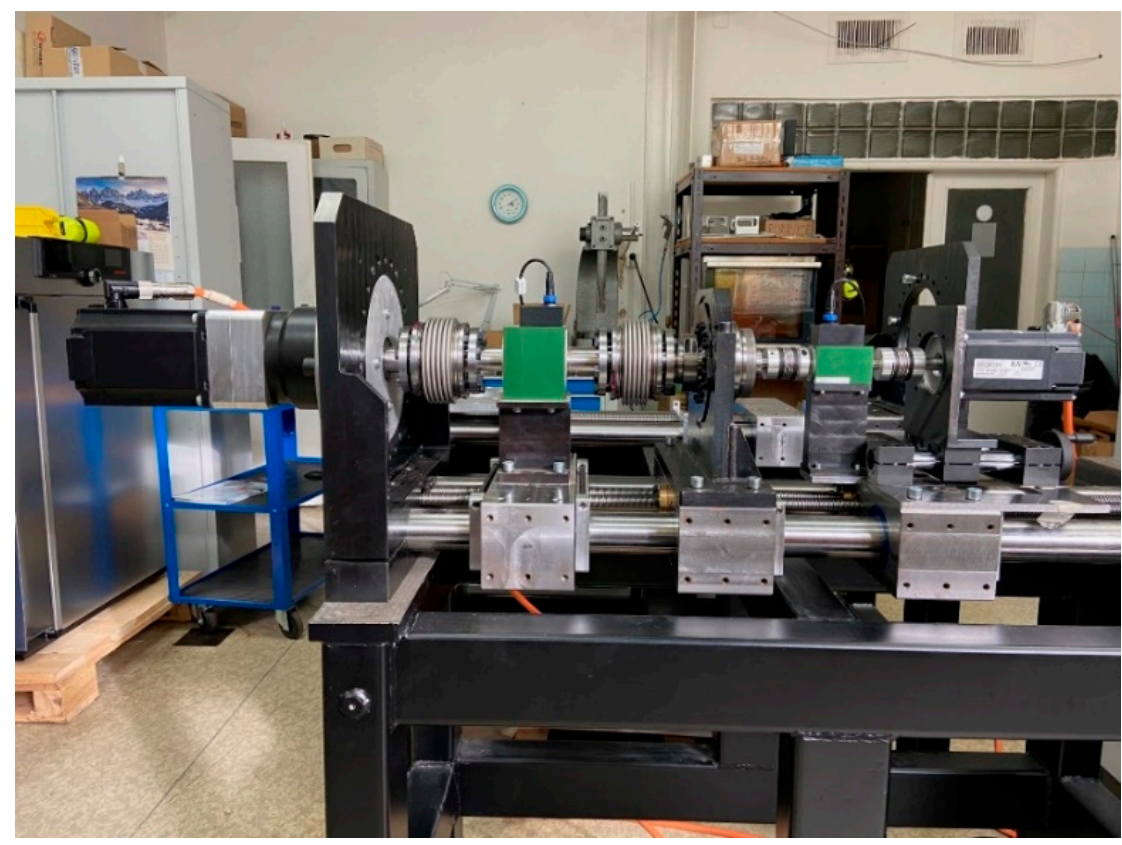

Figure 7. View of the stand in configuration B.

The following analyses were performed to assess the change in the characteristics of the bearing reducers during their trial run:

- Lubricant analysis,

- changes in surface microgeometry, wear or abrasive (adhesive) abrasion. Contamination of the oil fill with solid particles of an abrasive nature, which cause an increase in the rate of wear and accelerate the increase in the BR backlash;

- Analysis of temperature changes;

- Analysis of changes in starting torque-fluctuations;

- Analysis of H, LM changes;

- Analysis of changes in the system rigidity;

- Assessment of vibrations in the low frequency range;

- Assessment of vibrations in the high frequency range.

\section{Characteristics of the Diagnostic Methods Applied}

Lubricating oil analyses:

- $\quad$ ppm Fe abrasive particles were evaluated.

The following were applied to assess vibrations in the low frequency range:

- Velocity measurement method (jitter speed), [mm/s] unit, RMS detection.

- According to the ISO 10816-3: 2009 recommendation, FFT (Fast Fourier Transform) spectrum for the frequency range $10-800 \mathrm{~Hz}$.

- Enveloping Acceleration measurement method (method of measuring vibration acceleration in the high frequency range up to $10-20 \mathrm{kHz}$, through which the condition of roller bearings and gears is assessed), $\mathrm{gE}$ unit, PtP detection, for the frequency range $50-1000 \mathrm{~Hz}$, FFT spectrum and time log.

The following were used to assess vibrations in the high frequency range:

- (Jitter) acceleration measurement method, g unit, PtP detection, frequency range up to $16 \mathrm{kHz}, \mathrm{FFT}$ spectrum and time log

- Enveloping Acceleration measurement method, gE unit, PtP detection, frequency range up to $10 \mathrm{kHz}$ and up to $20 \mathrm{kHz}$, FFT spectrum and time log.

Diagnostic assessment methods in the field of acoustic emission and ultrasound: 
- SEE (Spectral Emitted Energy) measuring method-acoustic emissions (SKF), See unit, $\mathrm{PtP}$ detection, frequency range up to $600 \mathrm{kHz}$, FFT spectrum and time log.

- HFD measuring method-high frequency detection method (SKF), analysis of oscillations (accelerations) in the frequency range $40 \mathrm{kHz}$.

- Measuring method is used to assess lubrication, carrying capacity of oil film, metal contact, seizure, abrasion of contact surfaces (bearings and gears).

The so-called bump test was done on the BR-the search for natural frequencies of the measured system in the torsional and tipping direction. This is a traditional method of measurement. Performing a bump test involves the use of at least a two-channel frequency analyzer, impact hammer and accelerometer.

During the measurement, the LR TS 050 was fixed to the diagnostic equipment frame with screws. A mechanical arm with a weight of $2.5 \mathrm{~kg}$ was attached to its outlet flange. The excitation force was generated by the excitation impact hammer at the location of the weight at the end of the weight arm.

During the bump test, the oscillation amplitudes and frequencies are monitored by accelerometers and displayed as the area of the amplitude-frequency dependence. The most important information obtained is in the frequency deviations of the LR structure at their locations, and to a lesser extent, the attenuation values associated with these modes.

Subsequently, the BR was measured at a constant rotational frequency of $1000 \mathrm{rpm}$ at the input at a sinusoidal load (weight on the arm) in both directions of rotation (CW, CCW). The vibration sensor, PBC 356B18, was placed on the support body of the gearbox (in the vertical direction). At the same time, a repeated measurement of the start-up ramp was performed - the measurement of absolute vibrations during a continuous change of speed at the input, in the range of 0-2000 rpm and 0-3000 rpm. The aim of this measurement was to compare the effect of the onset of resonant events-amplification of the output arm vibration. Vibration sensors were placed on the output arm, at the point of the weight, in the radial and axial direction.

Temperature measurement was done on the BR in order to monitor temperature changes (BR heating) during the trial run process.

\section{Conducting Measurements of Characteristic Properties of Bearing Reducers during Their Trial Run \\ 5.1. Bearing Reducer Trial Run-Configuration A}

The measurement was performed in a type A configuration, i.e., the load was applied onto the arm by means of a mechanical weight. The measurements of the examined object were performed on 10 samples with a load of $50 \%$ TR at a constant rotational input frequency of $1000 \mathrm{rpm}$ over $48 \mathrm{~h}$. During the trial run mode, the temperature on the surface of the BR support body was measured and logged. Abrasion particle measurements were taken at eight-hour intervals throughout the BR trial run period. Bearing reducer TS 050 parameters measured before the trial run in configuration A are shown in Table 2.

A measurement of the starting BR TS 050 torque values was performed under the following parameters:

- Input rotation speed: $10 \mathrm{rpm}$.

- Number of output flange revolutions completed: 1 revolution.

- Number of shaft revolutions completed: 63 revolutions.

- Sensor sampling frequency: $200 \mathrm{smps} / \mathrm{s}$.

- Sensor resolution: 1:1.

- Ambient temperature: $21^{\circ} \mathrm{C} \pm 2$.

Test cycle:

- Torsional moment $\mathrm{M}_{\mathrm{t}}(\mathrm{m}=4.0 \mathrm{~kg}$ on the arm of $0.425 \mathrm{~m})$.

- When measuring $\mathrm{M}_{\mathrm{t}}$ loaded to tipping moment $\mathrm{Mc}=44 \mathrm{Nm}$.

- Average cycle torque $\mathrm{T}_{\text {ave }}=16 \mathrm{Nm}$.

- Average input speed $n_{a v e}=2054 \mathrm{rpm}$.

- No cycle pause $\geq$ load factor $Z=100 \%$. 
- $\quad$ Acceleration time to $1000 \mathrm{rpm} \mathrm{t}_{\mathrm{acc}}=0.5 \mathrm{~s}$.

- $\quad$ Reverse cycle S8.

Table 2. Bearing reducer TS 050 parameters measured before the trial run (configuration A).

\begin{tabular}{cccccc}
\hline No. & Type BR/Serial No & $\begin{array}{c}\text { Lost Motion } \\
\text { [arcmin] }\end{array}$ & $\begin{array}{c}\text { Hysteresis } \\
\text { [arcmin] }\end{array}$ & $\begin{array}{c}\text { Rm }(\mathbf{C W}) \\
{[\mathbf{N m}]}\end{array}$ & $\begin{array}{c}\text { Rm }(\mathbf{C C W}) \\
{[\mathbf{N m}]}\end{array}$ \\
\hline 1. & TS 050 s/n.1901 & 0.57 & 0.42 & 0.030 & 0.036 \\
2. & TS 050 s/n.1902 & 0.64 & 0.55 & 0.031 & 0.023 \\
3. & TS 050 s/n.1903 & 0.57 & 0.44 & 0.027 & 0.021 \\
4. & TS 050 s/n.1904 & 0.52 & 0.55 & 0.024 & 0.017 \\
5. & TS 050 s/n.1905 & 0.53 & 0.45 & 0.027 & 0.033 \\
6. & TS 050 s/n.1906 & 0.55 & 0.42 & 0.032 & 0.024 \\
7. & TS 050 s/n.1907 & 0.69 & 0.41 & 0.039 & 0.044 \\
8. & TS 050 s/n.1908 & 0.55 & 0.53 & 0.030 & 0.027 \\
9. & TS 050 s/n.1909 & 0.51 & 0.52 & 0.039 & 0.044 \\
10. & TS 050 s/n.1910 & 0.64 & 0.44 & 0.037 & 0.043 \\
\hline
\end{tabular}

The measurement of the Fe solids' concentration was carried out during the entire BR trial run in the (mechanical) weight application configuration, according to the conditions set out in Table 3. The measurement of temperature changes on the surface of the BR support body was performed using a sensor with a built-in magnet of the Alnico type, which is suitable for measuring the surface temperature of steel surfaces. The sensor was attached with a magnet. Temperature measurements were performed during the entire period $(48 \mathrm{~h}$ ) of the trial run at $1 \mathrm{~h}$ intervals. During the measurement, the alarm value was set at $60{ }^{\circ} \mathrm{C}$, which is the maximum permissible value set by the manufacturer on the BR support body. The summary values of the surface temperatures BR are shown in Figure 8.

Table 3. Values of solid abrasive particles during $48 \mathrm{~h}$ of the BR TS 050 trial run.

\begin{tabular}{|c|c|c|c|c|c|c|}
\hline No. & $\begin{array}{c}\text { Type BR/Serial } \\
\text { No }\end{array}$ & $\begin{array}{c}\text { Content } \\
\text { Fe (ppm) } \\
\text { after } 8 \mathrm{~h}\end{array}$ & $\begin{array}{c}\text { Content } \\
\text { Fe (ppm) } \\
\text { after } 16 \mathrm{~h}\end{array}$ & $\begin{array}{c}\text { Content } \\
\text { Fe (ppm) } \\
\text { after } 24 \mathrm{~h}\end{array}$ & $\begin{array}{l}\text { Content } \\
\text { Fe (ppm) } \\
\text { after } 32 \text { h }\end{array}$ & $\begin{array}{c}\text { Content } \\
\text { Fe (ppm) } \\
\text { after } 48 \mathrm{~h}\end{array}$ \\
\hline 1. & TS 050 s/n.1901 & 7 & 10 & 12 & 14 & 16 \\
\hline 2. & TS 050 s /n.1902 & 8 & 12 & 13 & 15 & 16 \\
\hline 3. & TS 050 s /n.1903 & 9 & 11 & 14 & 16 & 17 \\
\hline 4. & TS 050 s/n.1904 & 10 & 13 & 16 & 18 & 18 \\
\hline 5. & TS 050 s/n.1905 & 9 & 12 & 15 & 17 & 18 \\
\hline 6. & TS 050 s/n.1906 & 11 & 12 & 14 & 16 & 17 \\
\hline 7. & TS 050 s/n.1907 & 8 & 11 & 13 & 15 & 16 \\
\hline 8. & TS 050 s /n.1908 & 12 & 13 & 16 & 18 & 19 \\
\hline 9. & TS 050 s/n.1909 & 9 & 14 & 16 & 17 & 17 \\
\hline 10. & TS 050 s /n.1910 & 10 & 13 & 14 & 16 & 17 \\
\hline
\end{tabular}

After $48 \mathrm{~h}$ of the continuous trial run mode, diagnostics were performed by means of the so-called bump test. The aim of the test was to determine the natural frequencies of the measured BR 050 system in the torsional and tipping direction. The vibration sensor of the triaxial accelerometer PBC 356B18 was glued to the support body in the vertical direction. The accelerometer was mounted on a mechanical arm. The summary of the natural frequency values measured in the axial and radial direction for the individual BR samples is shown in Table 4. 


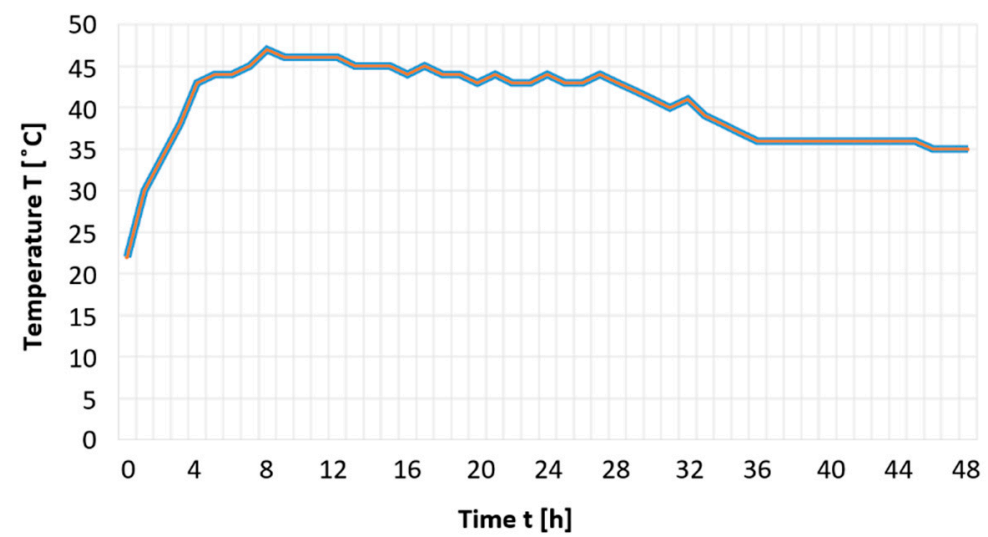

Figure 8. Graphical display of the courses of the temperature on the surface of the BR TS 050 support body during the trial run.

Table 4. Values of natural BR TS 050 frequencies measured after the trial run (configuration A).

\begin{tabular}{cccc}
\hline No. & $\begin{array}{c}\text { Type BR/Serial } \\
\text { No }\end{array}$ & $\begin{array}{c}\text { Natural Frequency } \\
\text { Radial-Torsional [RPM/Hz] }\end{array}$ & $\begin{array}{c}\text { Natural Frequency } \\
\text { Axially-Tipping [RPM/Hz] }\end{array}$ \\
\hline 1. & TS 050 s/n.1901 & $840 / 14.0$ & $1260 / 21.0$ \\
2. & TS 050 s/n.1902 & $825 / 13.0$ & $1210 / 20.0$ \\
3. & TS 050 s/n.1903 & $831 / 12.5$ & $1245 / 21.0$ \\
4. & TS 050 s/n.1904 & $844 / 14.0$ & $1270 / 20.0$ \\
5. & TS 050 s/n.1905 & $837 / 13.0$ & $1233 / 19.0$ \\
6. & TS 050 s/n.1906 & $833 / 12.0$ & $1250 / 18.5$ \\
7. & TS 050 s/n.1907 & $842 / 14.0$ & $1280 / 21.0$ \\
8. & TS 050 s/n.1908 & $830 / 13.0$ & $1310 / 22.0$ \\
9. & TS 050 s/n.1909 & $820 / 11.0$ & $1240 / 19.0$ \\
10. & TS 050 s/n.1910 & $835 / 11.5$ & $1260 / 20.0$ \\
\hline
\end{tabular}

Based on the conducted measurements, we can state that the natural frequency in the radial direction ranges between $820 \pm 10 \mathrm{rpm}$. At the same time, it can be stated that the natural frequency (critical speed) in the axial direction ranges between $1260 \pm 50 \mathrm{rpm}$. The starting torque (Rm) BR TS 050-63, s/n.1901 before the trial run of CW direction is shown in Figure 9, and that for CWW direction is in Figure 10.

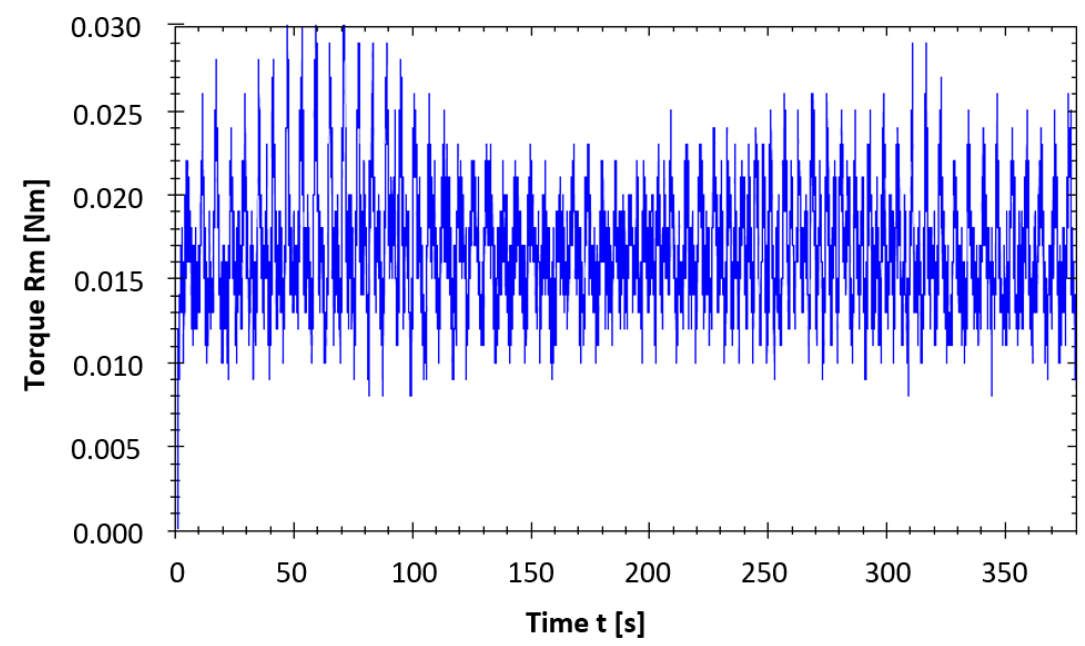

Figure 9. Starting torque (Rm) BR TS 050-63, s/n.1901—CW direction (before the trial run). 


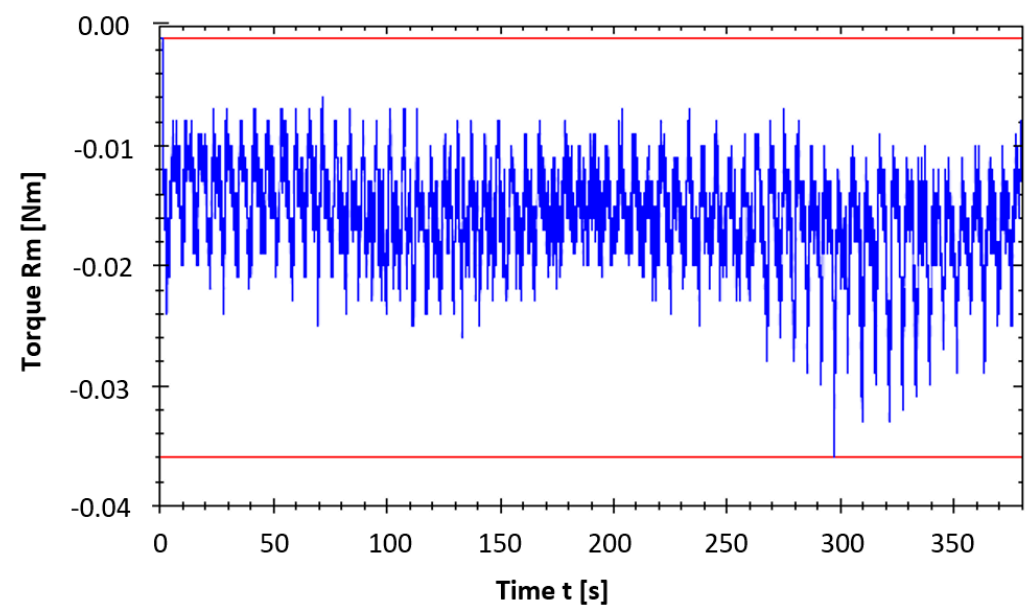

Figure 10. Starting torque (Rm) BR TS 050-63, s/n.1901—CCW direction (before the trial run).

Following the trial run mode and the collecting of the measurements of the reducer's natural frequencies, a summary of the initial information about the bearing reducers TS 050 with a gear ratio of 63 , necessary for evaluating the parameter changes, was obtained. Subsequent to the trial run, measurements of the LM, H, and Rm (CW-Figure 11, CCWFigure 12) parameters were conducted again, as they could have been affected by the trial run mode. The summary of the $\mathrm{LM}, \mathrm{H}$, and $\mathrm{Rm}(\mathrm{CW}, \mathrm{CCW})$ values measured for individual samples of the monitored BR parameters is shown in Table 5, and the course of the hysteresis curve BR TS 050-63, s/n.1901 after a 48 h-long trial run, in Figure 13.

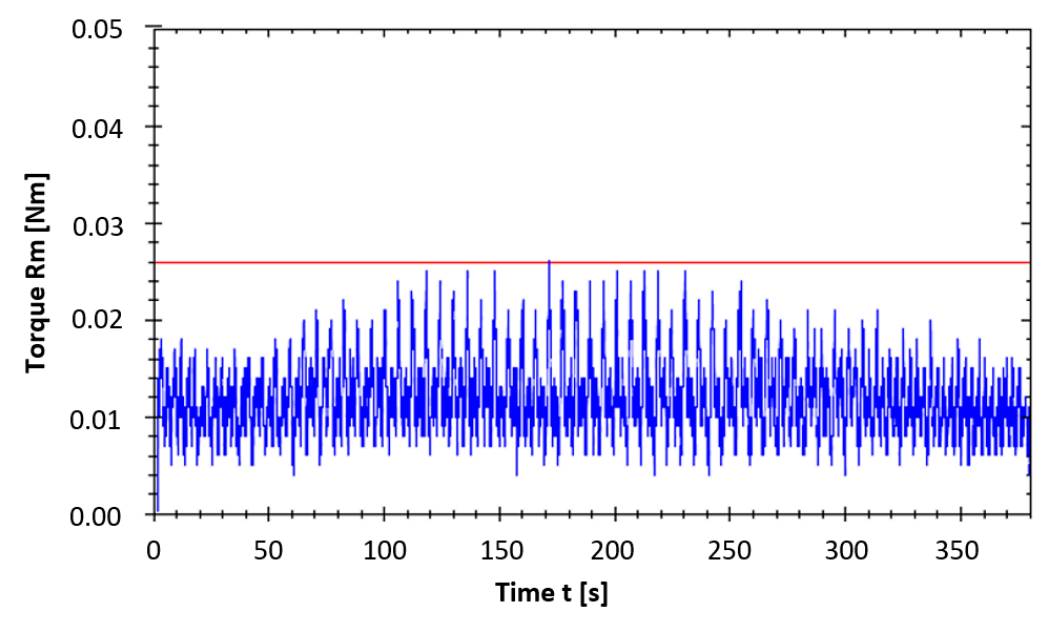

Figure 11. Starting torque BR TS 050-63, s/n.1901-CW direction (after the trial run).

Table 5. Bearing reducer TS 050 parameters measured after the trial run (A).

\begin{tabular}{|c|c|c|c|c|c|}
\hline No. & $\begin{array}{c}\text { Type BR/Serial } \\
\text { No. }\end{array}$ & $\begin{array}{l}\text { Lost Motion } \\
\text { [arcmin] }\end{array}$ & $\begin{array}{l}\text { Hysteresis } \\
\text { [arcmin] }\end{array}$ & $\begin{array}{c}\mathrm{Rm}(\mathrm{CW}) \\
{[\mathrm{Nm}]}\end{array}$ & $\begin{array}{c}\mathrm{Rm}(\mathrm{CCW}) \\
{[\mathrm{Nm}]}\end{array}$ \\
\hline 1. & TS 050 s/n.1901 & 0.57 & 0.45 & 0.026 & 0.023 \\
\hline 2. & TS $050 \mathrm{~s} / \mathrm{n} .1902$ & 0.64 & 0.59 & 0.025 & 0.019 \\
\hline 3. & TS $050 \mathrm{~s} / \mathrm{n} .1903$ & 0.57 & 0.51 & 0.021 & 0.017 \\
\hline 4. & TS 050 s/n.1904 & 0.52 & 0.64 & 0.019 & 0.015 \\
\hline 5. & TS $050 \mathrm{~s} / \mathrm{n} .1905$ & 0.53 & 0.49 & 0.022 & 0.024 \\
\hline 6. & TS 050 s/n.1906 & 0.55 & 0.47 & 0.028 & 0.020 \\
\hline 7. & TS 050 s/n.1907 & 0.69 & 0.45 & 0.032 & 0.032 \\
\hline 8. & TS $050 \mathrm{~s} / \mathrm{n} .1908$ & 0.55 & 0.62 & 0.024 & 0.023 \\
\hline 9. & TS 050 s/n.1909 & 0.51 & 0.59 & 0.030 & 0.038 \\
\hline 10. & TS 050 s/n.1910 & 0.64 & 0.52 & 0.029 & 0.037 \\
\hline
\end{tabular}




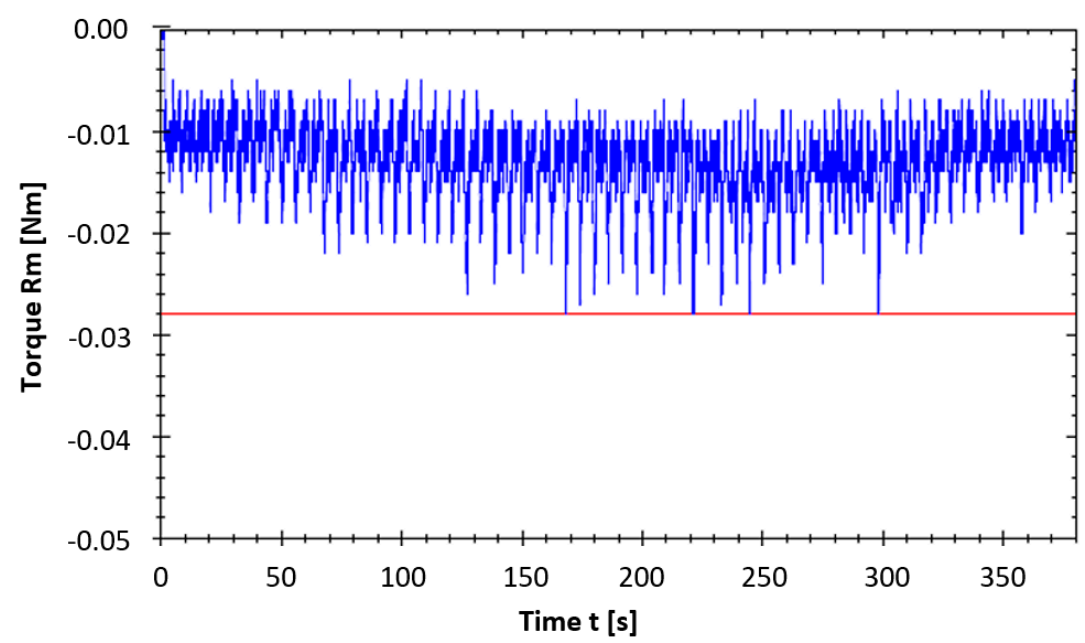

Figure 12. Starting torque BS TS 050-63, s/n.1901-CCW direction (after the trial run).

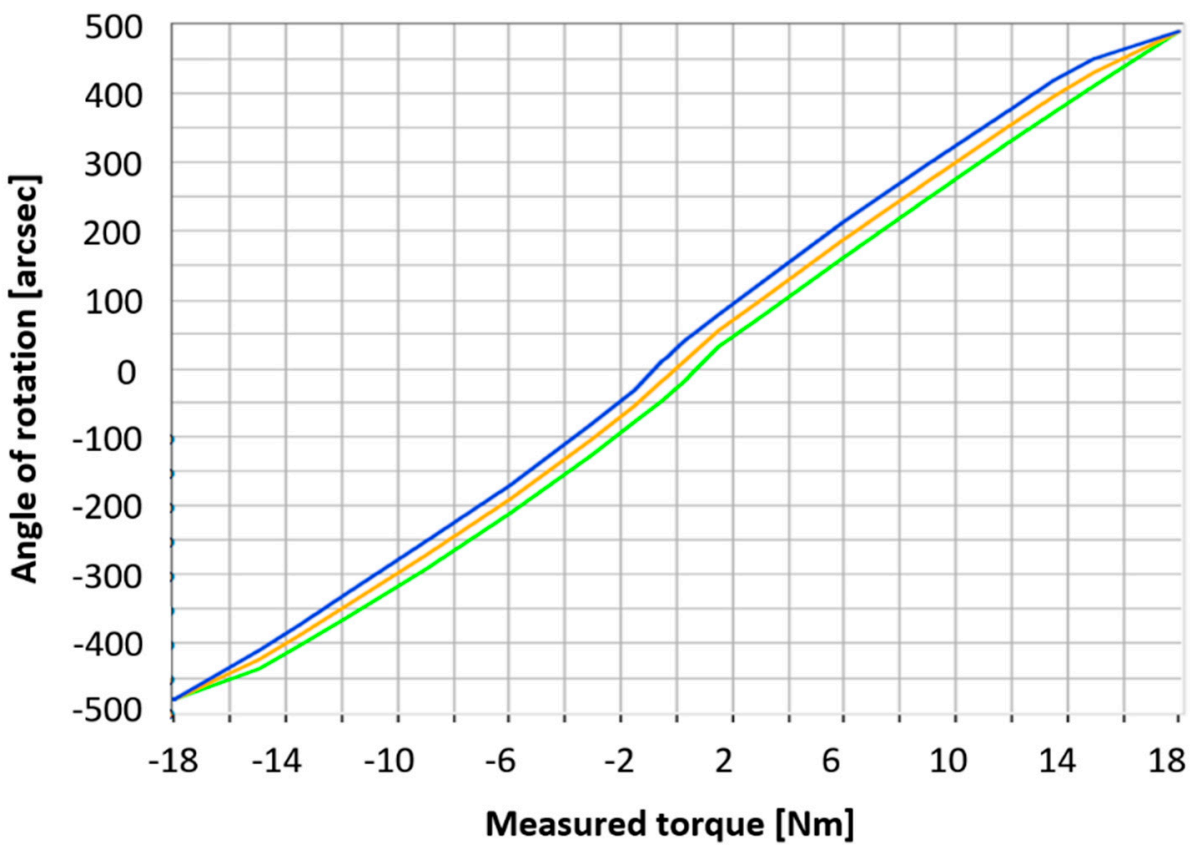

Figure 13. Course of hysteresis curve BR TS 050-63, s/n.1901 after 48 h-long trial run.

Summary of partial results from the application of MDS during the trial run of the TS 050 bearing reducer-weight load (mechanical weight at the end of the arm) applied during the trial run:

Measurements were conducted on 10 BR 050-63 samples. Before the trial run, we performed a series of measurements on the samples to identify the factual state of BR. After an initial $48 \mathrm{~h}$ trial run with a load factor of $9 \mathrm{Nm}$ at the output, there was a decrease in the starting torque in both directions, i.e., the $\mathrm{CW}, \mathrm{CCW}$, which can be attributed to the starting of kinematic pairs during mechanical transmission. After the trial run, the parameters, such as lost motion (LM), remained unchanged. In the case of the hysteresis parameter $(\mathrm{H})$, there was a slight growth in the increase in value, but the value of the difference itself is so small that no significant effect needs to be attributed thereto. The range of change is 0.03 to 0.09 arcmin (Table 6). 
Table 6. Difference of measured parameters LR 050 before and after the trial run (configuration A).

\begin{tabular}{|c|c|c|c|c|c|}
\hline No. & $\begin{array}{c}\text { Type BR/Serial } \\
\text { No. }\end{array}$ & $\begin{array}{l}\text { Lost Motion } \\
\text { [Arcmin] }\end{array}$ & $\begin{array}{l}\text { Hysteresis } \\
\text { [Arcmin] }\end{array}$ & $\begin{array}{c}\mathrm{Rm}(\mathrm{CW}) \\
{[\mathrm{Nm}]}\end{array}$ & $\begin{array}{c}\mathrm{Rm}(\mathrm{CCW}) \\
{[\mathrm{Nm}]}\end{array}$ \\
\hline 1. & TS 050 s/n.1901 & 0 & +0.03 & -0.004 & -0.013 \\
\hline 2. & TS 050 s/n.1902 & 0 & +0.04 & -0.006 & -0.004 \\
\hline 3. & TS $050 \mathrm{~s} / \mathrm{n} .1903$ & 0 & +0.07 & -0.006 & -0.004 \\
\hline 4. & TS $050 \mathrm{~s} / \mathrm{n} .1904$ & 0 & +0.09 & -0.005 & -0.002 \\
\hline 5. & TS $050 \mathrm{~s} / \mathrm{n} .1905$ & 0 & +0.04 & -0.005 & -0.009 \\
\hline 6. & TS 050 s/n.1906 & 0 & +0.05 & -0.004 & -0.004 \\
\hline 7. & TS 050 s/n.1907 & 0 & +0.04 & -0.007 & -0.012 \\
\hline 8. & TS $050 \mathrm{~s} / \mathrm{n} .1908$ & 0 & +0.09 & -0.006 & -0.004 \\
\hline 9. & TS 050 s/n.1909 & 0 & +0.07 & -0.009 & -0.004 \\
\hline 10. & TS $050 \mathrm{~s} / \mathrm{n} .1910$ & 0 & +0.08 & -0.008 & -0.006 \\
\hline
\end{tabular}

From the course of the temperature values measured on the support body after the initial temperature rise to $47^{\circ} \mathrm{C}$, it is apparent that the temperatures stabilized at $36{ }^{\circ} \mathrm{C}$ after about $35 \mathrm{~h}$. The maximum degree of contamination of the PG TT1 lubricant with Fe solid particles was 19 ppm Fe.

\subsection{Trial Run of the Gear Reducer in Configuration B}

The measurement was conducted in a type B configuration, i.e., under the load from the load applying servomotor. The measurements of the examined object No. 1 were conducted on 10 samples with the load applied to $50 \%$ TR at a constant rotational input frequency of $1000 \mathrm{rpm}$ over $48 \mathrm{~h}$. During the trial run mode, the temperature on the surface of the BR support body was measured and logged. Abrasion particle measurements were taken at eight-hour intervals throughout the BR trial run period. As the load application, the drive with reducer B\&R servomotor type 8LSA55 was used (DA030S000-3 with planetary reducer B\&R type 8GP50-155-050S1L5).

Prior to the bearing reducer TS 050 trial run process itself, the initial parameter measurements were performed, which are necessary for comparing diagnostic changes after the trial run, as well as for qualitative assessment of the influence of the type of the load (mechanical weight on the arm versus the load applying drive) during the trial run mode on the starting torque and the starting torque fluctuation. The measured values of the starting torques (torque fluctuations) BR 050 were recorded and evaluated by means of a Burster sensor + DigiVision working environment, similar to the measurements in configuration A. Bearing reducer TS 050 parameters measured before the trial run in configuration B are shown in Table 7.

Measurement of the starting BR TS 050 torque values was performed under the following parameters:

- Input rotation speed: $10 \mathrm{rpm}$.

- Number of output flange revolutions completed: 1 revolution.

- Number of shaft revolutions completed: 63 revolutions.

- Sensor sampling frequency: $200 \mathrm{smps} / \mathrm{s}$.

- $\quad$ Sensor resolution: 1:1.

- Ambient temperature: $21^{\circ} \mathrm{C} \pm 2$.

Test cycle:

- Torsional moment caused by the load applying drive.

- $\quad$ Average cycle torque $\mathrm{T}_{\mathrm{ave}}=16.0 \mathrm{Nm}$.

- $\quad$ Average input speed $\mathrm{n}_{\mathrm{ave}}=2054 \mathrm{rpm}$.

- Acceleration time to $1000 \mathrm{rpm} \mathrm{t}_{\mathrm{acc}}=0.5 \mathrm{~s} / 1000 \mathrm{rpm}$.

- $\quad$ Reverse cycle S8.

The measurement of the Fe solids' concentration (Table 8) was performed during the entire BR trial run period in the load applied by drive configuration (motor versus motor). 
The measurement was conducted with an SDM-72 evaluation device. The graphic display of the course of temperature changes during the trial run is shown in Figure 14.

Table 7. Bearing reducer TS 050 parameters measured before the trial run (configuration B).

\begin{tabular}{cccccc}
\hline No. & $\begin{array}{c}\text { Type BR/Serial } \\
\text { No. }\end{array}$ & $\begin{array}{c}\text { Lost Motion } \\
\text { [arcmin] }\end{array}$ & $\begin{array}{c}\text { Hysteresis } \\
\text { [arcmin] }\end{array}$ & $\begin{array}{c}\text { Rm }(\mathbf{C W}) \\
{[\mathbf{N m}]}\end{array}$ & $\begin{array}{c}\text { Rm }(\mathbf{C C W}) \\
{[\mathbf{N m}]}\end{array}$ \\
\hline 1. & TS 050 s/n.1911 & 0.73 & 0.55 & 0.045 & 0.043 \\
2. & TS 050 s/n.1912 & 0.65 & 0.95 & 0.035 & 0.041 \\
3. & TS 050 s/n.1913 & 0.80 & 1.11 & 0.040 & 0.046 \\
4. & TS 050 s/n.1914 & 0.78 & 0.63 & 0.032 & 0.038 \\
5. & TS 050 s/n.1915 & 0.62 & 1.00 & 0.042 & 0.050 \\
6. & TS 050 s/n.1916 & 0.71 & 0.82 & 0.051 & 0.046 \\
7. & TS 050 s/n.1917 & 0.82 & 1.04 & 0.036 & 0.040 \\
8. & TS 050 s/n.1918 & 0.90 & 0.74 & 0.044 & 0.042 \\
9. & TS 050 s/n.1919 & 0.55 & 0.67 & 0.032 & 0.039 \\
10. & TS 050 s/n.1920 & 0.76 & 0.90 & 0.028 & 0.034 \\
\hline
\end{tabular}

Table 8. Solid abrasive particle values over $48 \mathrm{~h}$ of the BR TS 050 trial run.

\begin{tabular}{|c|c|c|c|c|c|c|}
\hline No. & $\begin{array}{c}\text { Type BR/Serial } \\
\text { No. }\end{array}$ & $\begin{array}{l}\text { Content Fe } \\
(p p m) \\
\text { after } 8 \mathrm{~h}\end{array}$ & $\begin{array}{l}\text { Content Fe } \\
\text { (ppm) } \\
\text { after } 16 \mathrm{~h}\end{array}$ & $\begin{array}{l}\text { Content Fe } \\
\text { (ppm) } \\
\text { after } 24 \mathrm{~h}\end{array}$ & $\begin{array}{c}\text { Content Fe } \\
\text { (ppm) } \\
\text { after } 32 \mathrm{~h}\end{array}$ & $\begin{array}{l}\text { Content Fe } \\
\text { (ppm) } \\
\text { after } 48 \mathrm{~h}\end{array}$ \\
\hline 1. & TS $050 \mathrm{~s} / \mathrm{n} .1911$ & 9 & 10 & 10 & 14 & 14 \\
\hline 2. & TS 050 s/n.1912 & 7 & 8 & 11 & 12 & 12 \\
\hline 3. & TS $050 \mathrm{~s} / \mathrm{n} .1913$ & 11 & 12 & 12 & 14 & 15 \\
\hline 4. & TS 050 s/n.1914 & 8 & 10 & 11 & 12 & 13 \\
\hline 5. & TS $050 \mathrm{~s} / \mathrm{n} .1915$ & 7 & 9 & 10 & 11 & 13 \\
\hline 6. & TS $050 \mathrm{~s} / \mathrm{n} .1916$ & 9 & 11 & 12 & 14 & 14 \\
\hline 7. & TS $050 \mathrm{~s} / \mathrm{n} .1917$ & 8 & 9 & 11 & 13 & 13 \\
\hline 8. & TS 050 s/n.1918 & 7 & 10 & 12 & 14 & 14 \\
\hline 9. & TS $050 \mathrm{~s} / \mathrm{n} .1919$ & 9 & 9 & 11 & 13 & 14 \\
\hline 10. & TS 050 s /n.1920 & 7 & 8 & 9 & 11 & 11 \\
\hline
\end{tabular}

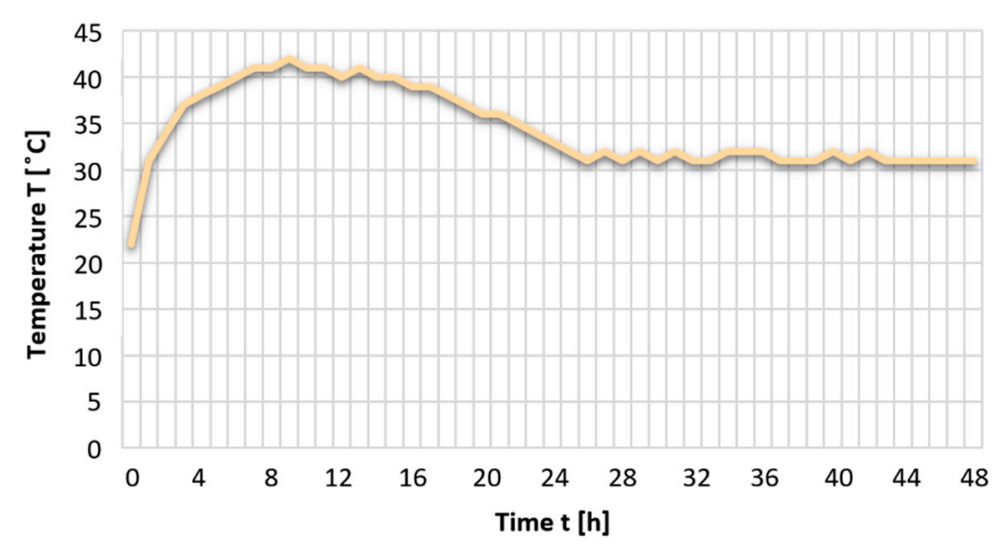

Figure 14. Graphic display of the course of temperature changes during the trial run.

After a $48 \mathrm{~h}$ continuous trial run mode, diagnostics were performed to determine the natural frequencies of the measured BR 050 system in the torsional direction, only. Since only a torsional load can be generated by the load applying servomotor, the natural frequencies in the tipping direction have not been identified. The vibration sensor of the triaxial PBC 356B18 accelerometer was glued to the support body in the vertical direction. The accelerometer was mounted on the mechanical bracket of the frame. The summary of the natural frequency values measured in the axial and radial direction for the individual BR samples is shown in Table 9. Starting torque (Rm) BR TS 050-63, s/n.1911 before the trial run of CW direction is shown in Figure 15 and CWW direction, in Figure 16. 
Table 9. Values of natural BR TS 050 frequencies measured after the trial run (configuration B).

\begin{tabular}{ccc}
\hline No. & Type BR/Serial No. & Natural Frequency Radial-Torsional [rpm/Hz] \\
\hline 1. & TS $050 \mathrm{~s} / \mathrm{n} .1911$ & $820 / 11.3$ \\
2. & TS $050 \mathrm{~s} / \mathrm{n} .1912$ & $830 / 12.0$ \\
3. & TS $050 \mathrm{~s} / \mathrm{n} .1913$ & $815 / 13.0$ \\
4. & TS $050 \mathrm{~s} / \mathrm{n} .1914$ & $835 / 12.0$ \\
5. & TS 050 s/n.1915 & $824 / 11.5$ \\
6. & TS 050 s/n.1916 & $822 / 13.0$ \\
7. & TS 050 s/n.1917 & $838 / 12.5$ \\
8. & TS 050 s/n.1918 & $832 / 13.0$ \\
9. & TS 050 s/n.1919 & $840 / 11.0$ \\
10. & TS 050 s/n.1920 & $837 / 14.0$ \\
\hline
\end{tabular}

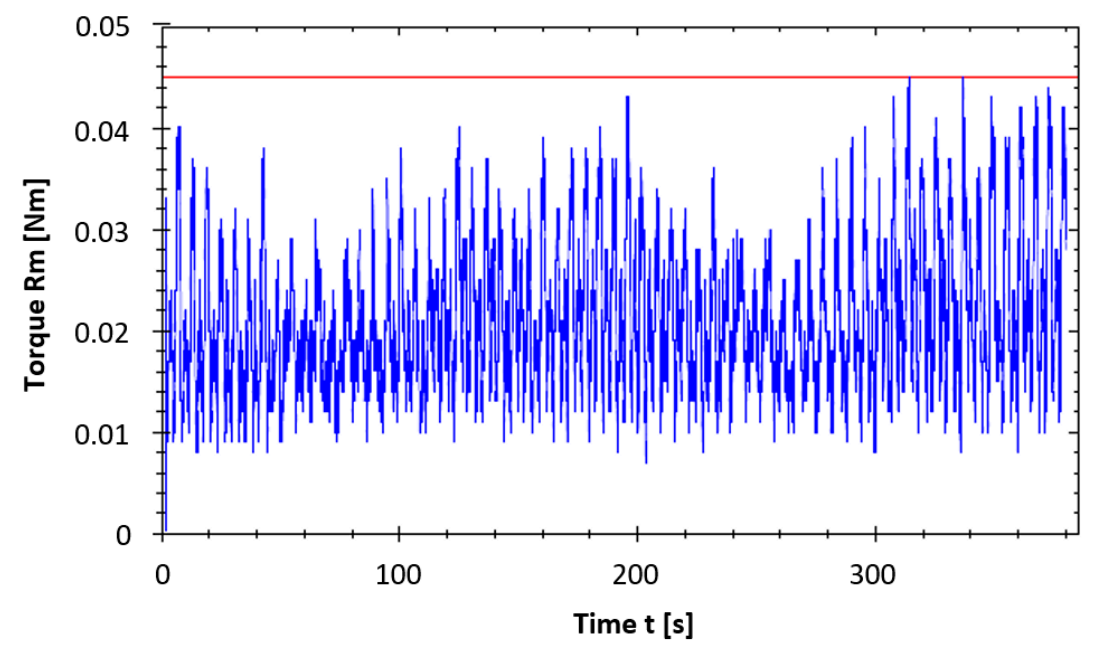

Figure 15. Starting torque (Rm) BR TS 050-63, s/n.1911—CW direction (before the trial run).

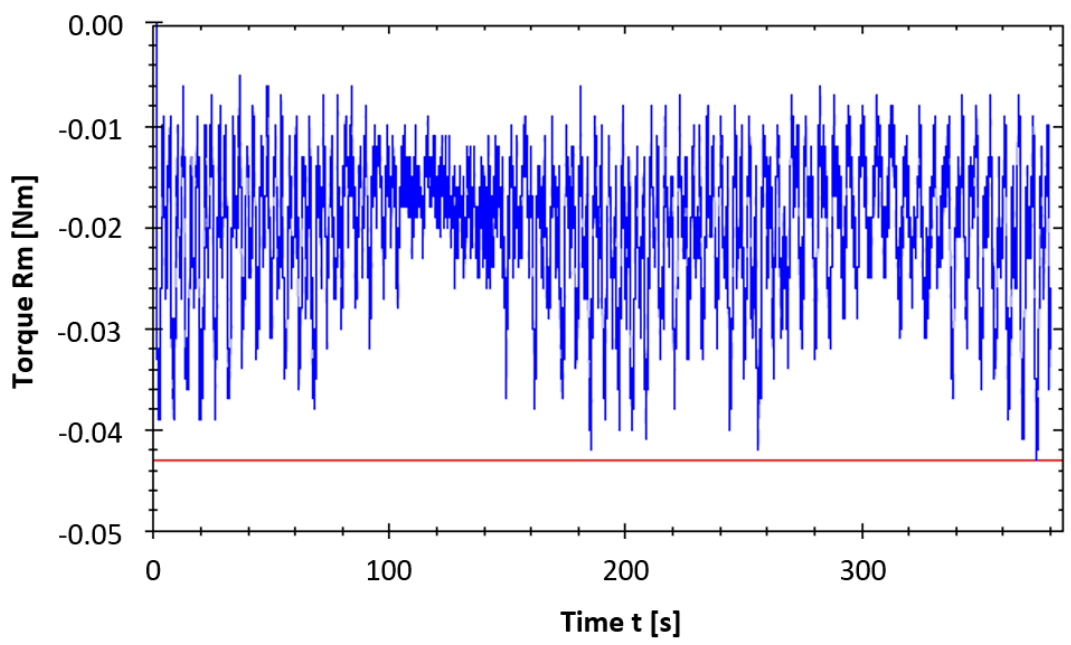

Figure 16. Starting torque (Rm) BR TS 050-63, s/n.1911-CCW direction (before the trial run).

Following the trial run mode and the collecting of the measurements of the reducer's natural frequencies, a summary of the initial information about the bearing reducers TS 050 with a gear ratio of 63, necessary for evaluating the parameter changes, was obtained. Subsequent to the trial run, measurements of the $\mathrm{LM}, \mathrm{H}$, and $\mathrm{Rm}(\mathrm{CW}, \mathrm{CCW})$ parameters were conducted again, as they could have been affected by the trial run mode (Table 10). A graphical representation of the course of $\mathrm{Rm}(\mathrm{CW}, \mathrm{CCW})$ measurement is shown in Figures 17 and 18. For the sake of comparability of the individual results before the trial 
run, after the trial run, and before the actual operation, the measurements of the BR characteristics were conducted in the same position as the support body and the output flange through the mark created in the first measurement. A graphical representation of the course of LM and H measurements of a selected BR TS 050-63, s/n.1911 representative is shown in Figure 19.

Table 10. Bearing reducer TS 050 parameters measured after the trial run (configuration B).

\begin{tabular}{cccccc}
\hline No. & $\begin{array}{c}\text { Type BR/Serial } \\
\text { No. }\end{array}$ & $\begin{array}{c}\text { Lost Motion } \\
\text { [arcmin] }\end{array}$ & $\begin{array}{c}\text { Hysteresis } \\
\text { [arcmin] }\end{array}$ & $\begin{array}{c}\text { Rm }(\mathbf{C W}) \\
{[\mathbf{N m}]}\end{array}$ & $\begin{array}{c}\text { Rm }(\mathbf{C C W}) \\
{[\mathbf{N m}]}\end{array}$ \\
\hline 1. & TS 050 s/n.1911 & 0.73 & 0.59 & 0.026 & 0.025 \\
2. & TS 050 s/n.1912 & 0.65 & 1.00 & 0.030 & 0.028 \\
3. & TS 050 s/n.1913 & 0.80 & 1.13 & 0.028 & 0.031 \\
4. & TS 050 s/n.1914 & 0.78 & 0.65 & 0.025 & 0.026 \\
5. & TS 050 s/n.1915 & 0.62 & 1.05 & 0.036 & 0.029 \\
6. & TS 050 s/n.1916 & 0.71 & 0.84 & 0.030 & 0.032 \\
7. & TS 050 s/n.1917 & 0.82 & 1.08 & 0.024 & 0.028 \\
8. & TS 050 s/n.1918 & 0.90 & 0.75 & 0.029 & 0.030 \\
9. & TS 050 s/n.1919 & 0.55 & 0.70 & 0.020 & 0.027 \\
10. & TS 050 s/n.1920 & 0.76 & 0.93 & 0.021 & 0.024 \\
\hline
\end{tabular}

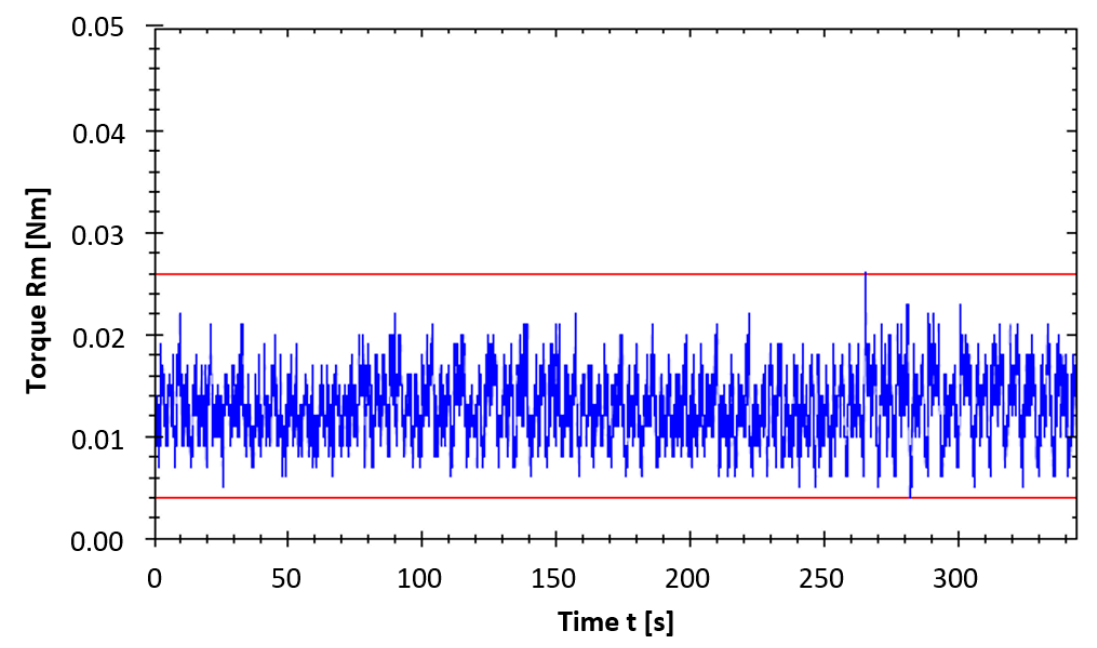

Figure 17. Starting torque (Rm) BR TS 050-63, s/n.1911-CW direction (after the trial run).

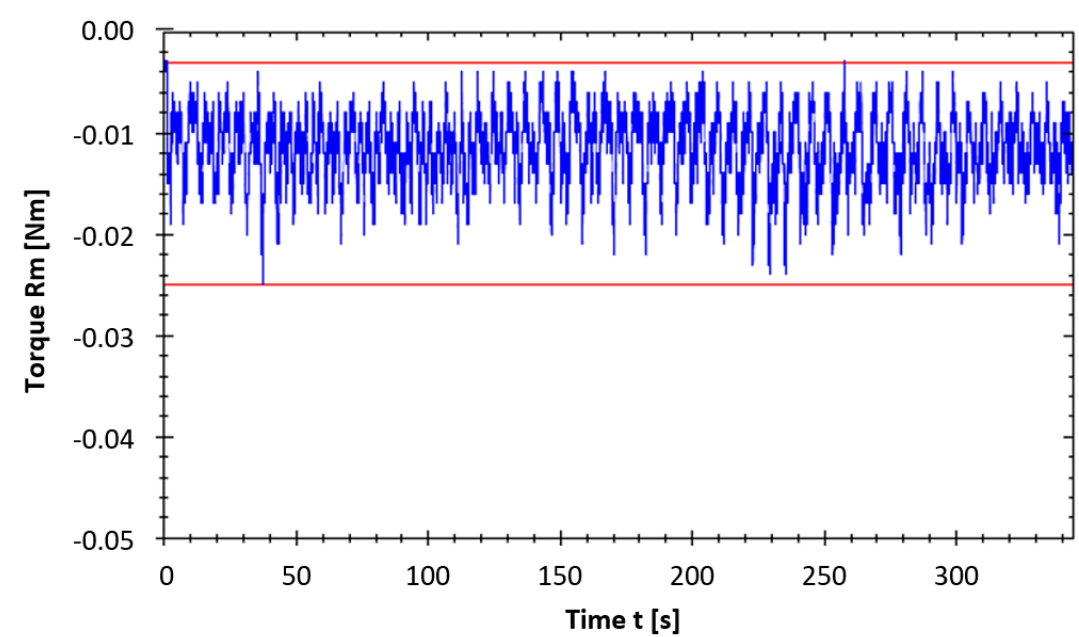

Figure 18. Starting torque (Rm) BR TS 050-63, s/n.1911-CCW direction (after the trial run). 


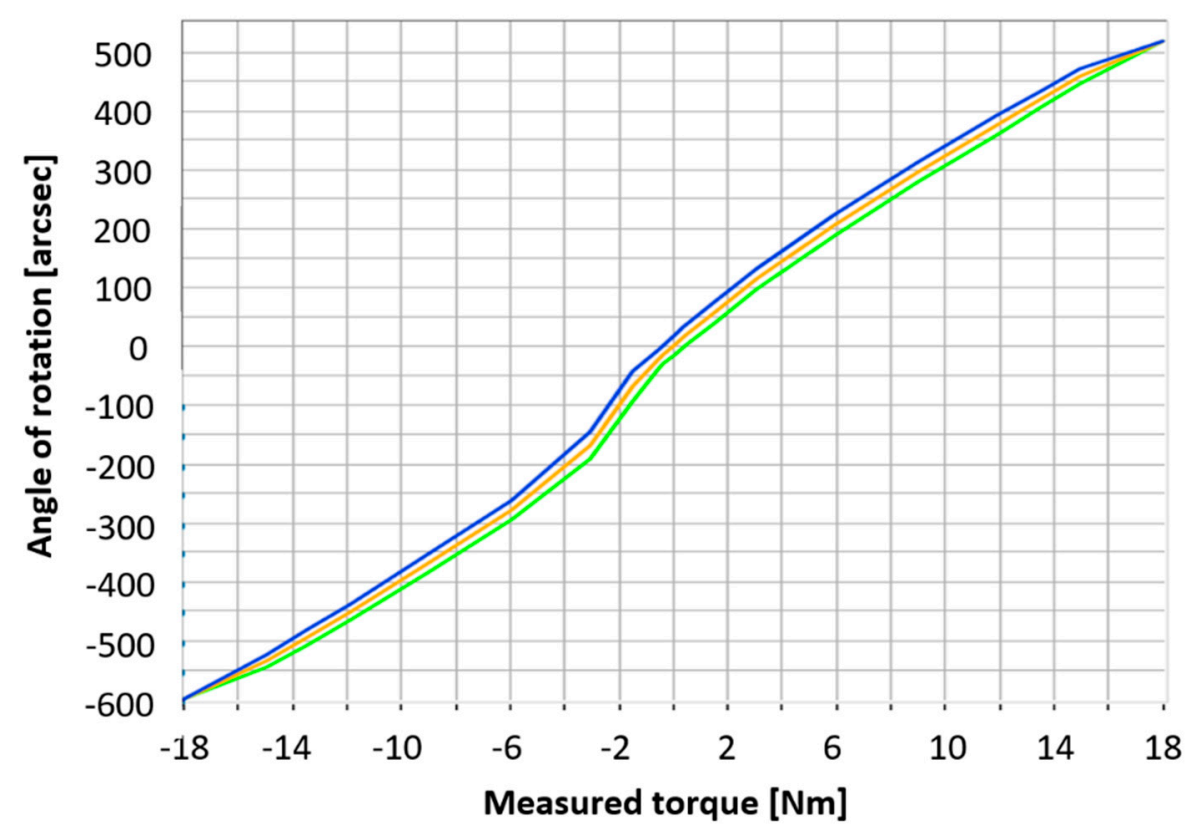

Figure 19. Course of the hysteresis curve BR TS 050-63, s/n.1911.

Summary of partial results from MDS during the trial run of the TS 050 bearing reducer-loading by the load application servomotor during the trial run:

Measurements were conducted on 10 BR TS 050-63 samples. Before the trial run, we performed a series of measurements on the samples to identify the factual state of BR. After an initial $48 \mathrm{~h}$ trial run with a load factor of $9 \mathrm{Nm}$ at the output, there was a decrease in the starting torque in both directions, i.e., the $\mathrm{CW}, \mathrm{CCW}$, which can be attributed to the starting of kinematic pairs during mechanical transmission. After the trial run, the parameters, such as lost motion (LM), remained unchanged. In the case of the hysteresis parameter $(\mathrm{H})$, there was a slight growth in the increase in value, but the value of the difference itself is so small that no significant effect needs to be attributed thereto. The range of change is 0.01 to 0.05 arcmin (Table 11).

Table 11. Difference of measured parameters LR 050 before and after the trial run (configuration B).

\begin{tabular}{|c|c|c|c|c|c|}
\hline No. & $\begin{array}{c}\text { Type BR/Serial } \\
\text { No. }\end{array}$ & $\begin{array}{l}\text { Lost Motion } \\
\text { [arcmin] }\end{array}$ & $\begin{array}{l}\text { Hysteresis } \\
\text { [arcmin] }\end{array}$ & $\begin{array}{c}\mathrm{Rm}(\mathrm{CW}) \\
{[\mathrm{Nm}]}\end{array}$ & $\begin{array}{c}\mathrm{Rm}(\mathrm{CCW}) \\
{[\mathrm{Nm}]}\end{array}$ \\
\hline 1. & TS 050 s/n.1911 & 0 & +0.04 & -0.019 & -0.018 \\
\hline 2. & TS 050 s/n.1912 & 0 & +0.05 & -0.005 & -0.013 \\
\hline 3. & TS $050 \mathrm{~s} / \mathrm{n} .1913$ & 0 & +0.02 & -0.012 & -0.015 \\
\hline 4. & TS 050 s/n.1914 & 0 & +0.02 & -0.007 & -0.012 \\
\hline 5. & TS $050 \mathrm{~s} / \mathrm{n} .1915$ & 0 & +0.05 & -0.006 & -0.021 \\
\hline 6. & TS 050 s/n.1916 & 0 & +0.02 & -0.021 & -0.014 \\
\hline 7. & TS $050 \mathrm{~s} / \mathrm{n} .1917$ & 0 & +0.04 & -0.012 & -0.012 \\
\hline 8. & TS $050 \mathrm{~s} / \mathrm{n} .1918$ & 0 & +0.01 & -0.015 & -0.012 \\
\hline 9. & TS 050 s/n.1919 & 0 & +0.03 & -0.012 & -0.012 \\
\hline 10. & TS 050 s/n.1920 & 0 & +0.03 & -0.007 & -0.010 \\
\hline
\end{tabular}

From the course of the temperature values measured on the support body after the initial temperature rise to $42{ }^{\circ} \mathrm{C}$, it is apparent that the temperatures stabilized at $31{ }^{\circ} \mathrm{C}$ after about $26 \mathrm{~h}$. The maximum degree of contamination of the PG TT1 lubricant with Fe solid particles was $15 \mathrm{ppm}$ Fe. 


\section{Evaluation of Results and Qualitative Assessment of the Impact of the Load during the Trial Run Mode}

The examined object No. 1 BR TR 050 with a gear ratio of 63 was subjected to two types of the trial run mode. Configuration A represented a load placed on the arm, represented by a mechanical weight. Configuration $B$ represented the load applied by the drive, the so-called motor versus motor. Diagnostic measurements of hysteresis, lost motion, starting torque, temperature and analysis of Fe abrasive particles for Castrol Tribol GR TT1 PD lubricant, suitable for high load applications and designed for long-term lubrication of roller bearings and the like, were done during the trials. Based on the measurements and analyses, it is possible to state the following:

- From the point of view of measuring the lost motion and hysteresis: The choice of the type of load during the BR trial run had no effect on the change in the values of the lost motion parameter. The monitored hysteresis parameters showed a negligible increase in values. The hysteresis curve is a variable nonlinearity and depends on the position of rotation of the output flange and the perfection of component production.

- From the point of view of measuring the starting torque: The choice of the type of load in the BR trial run had a demonstrable influence on the values of the parameter monitored-the starting torque and fluctuation of the starting torque. In the trial run with a load, a sinusoidal load is applied to the kinematic pairs, which are evenly loaded by a servomotor with a torque sensor (controlled torque value) during the load application process by the drive. In both trial run methods, the surfaces were smoothed, which was reflected in the torque fluctuation-a drop in the peaks. A decrease in the mean value of the starting torque was recorded when the load was applied by the drive.

- From the point of view of temperature measurement: After the initial increase in the surface temperature BR, the friction regime stabilized, and the temperatures decreased and became stable. The alarm value was not exceeded during the measurement, which can be seen in Figure 20.

- In terms of the lubricant condition: After the initial phase of the relative trial run, the Castrol Tribol GR TT1 PD lubricant used showed a satisfactory Fe content of abrasive particles (all sample values were below the recommended limit).

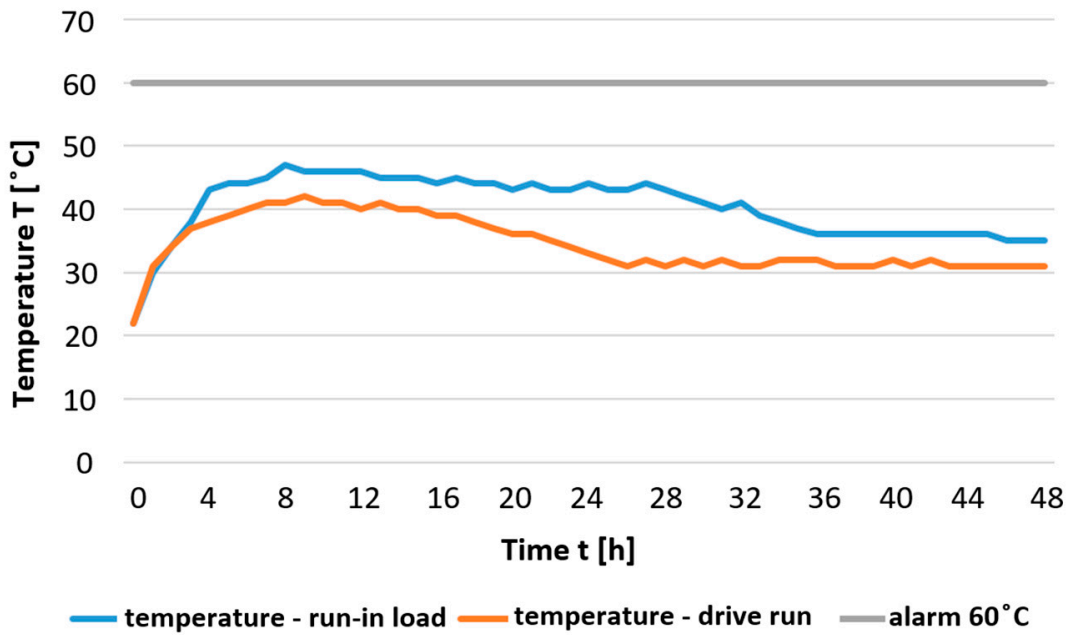

Figure 20. Course of temperatures on the BR TS 050 support body over a $48 \mathrm{~h}$ mode.

\section{Conclusions}

Reduction mechanisms, such as the high-precision bearing reducers of today's drive units in the field of machine tools and automation, are state-of-the-art and technologically advanced. Subjecting such mechanisms to a trial run is important. The development of new materials, lubricants, smaller production tolerances and new final technologies have 
reduced the trial run length, but it is nevertheless irresponsible to apply the full load to the reduction mechanism right from the start. The obligatory test operation cannot be considered a fully fledged trial run, as the test operation mostly serves the purpose of verifying the functionality of the reduction mechanism.

In the field of mechanical engineering technology of surface production, new technologies enable the production of surfaces to a precisely defined value. Specific properties are characteristic of each surface of a component material. Each bearing reducer component that comes into contact with another surface must adjust its position to the opposite component. In metal-to-metal contact, friction occurs. Friction increases metal wear. Each reduction mechanism includes rolling elements and bearings that reduce friction by allowing the two surfaces to roll relative to each other, thereby reducing the amount of friction generated. It is now considered a standard for components of high-precision reducers to be deburred, demagnetized and washed.

Research in this area has mapped in detail the impact on all the essential variables' characteristic of the high-precision reducer properties. The trial run was carried out in both recommended configurations of the load application onto the reducers, namely by means of a mechanical weight on the arm and by applying the load through a servomotor.

Based on the research carried out, it is possible to recommend that each user, after installing the bearing reducer in the appropriate alignment, does a trial run during operation for at least $48 \mathrm{~h}$ with a $50 \%$ TR load under the nominal torque and a maximum speed of $1000 \mathrm{rpm}$. In case of the oil version, it is recommended to change the entire oil content after the first $100 \mathrm{~h}$ of operation following the trial run.

At the same time, based on the research documented above, a methodology was established for measuring the important properties of high-precision reducers in connection with their trial run, which consists of the following steps:

- Reducer trial run over $48 \mathrm{~h}$, max. $60{ }^{\circ} \mathrm{C}$ temperature NT, 50\% TR at max. $1000 \mathrm{rpm}$.

- Measurement of abrasion Fe particles-max. Fe content of particles 50 ppm.

- Measurement of the reducer starting torque-input $10 \mathrm{rpm}$, upon completion of one rotation of the output BR member, at the sampling frequency of the sensor of 200 samples per second.

- Measurement of hysteresis $(\mathrm{H})$ and lost motion (LM) - in load-free state, $\mathrm{TR}=100 \%$ $\mathrm{Nm}$ in both directions (CW, CCW), evaluation at $3 \%$ TR load.

- Angular transmission error measurement (ATE) - in load-free state, output $0-720^{\circ}$, in both directions (CW, CCW).

- Repeated accuracy measurement-output rotation $1800^{\circ}$, eight desired positions at $360^{\circ}$.

This methodology unifies our approach to measuring the static and dynamic properties of high-precision reducers to identify their critical parameters and positioning accuracy.

The article points out two possibilities of running-in bearing reducers. The run-in was performed by a mechanical weight on the arm and by a load servomotor. The research showed that the choice of the load has a negligible effect on the values of lost motion and hysteresis, but it has a demonstrable effect on the values of the monitored parameterstarting torque and fluctuation of starting torque. However, in both trial run methods, the surfaces were smoothed, which was reflected in the torque fluctuation-a drop in the peaks. At the same time, after extensive research, it can be stated that the correct running-in of bearing reducers after their commissioning means the improvement of all parameters that characterize the static and dynamic parameters of high-precision reducers.

Author Contributions: M.K. conceived and designed the experiments, M.P. processed data and wrote the paper, M.T. analyzed and evaluated data, P.B. and J.K. data curation, and D.P. performed the experiments and measurements. All authors have read and agreed to the published version of the manuscript.

Funding: This research received no external funding. 
Institutional Review Board Statement: Not applicable.

Informed Consent Statement: Not applicable.

Data Availability Statement: Not applicable.

Acknowledgments: This paper has been elaborated in the framework of the project VEGA 1/0051/20 and project VEGA 1/0026/19.

Conflicts of Interest: The authors declare no conflict of interest. The founding sponsors had no role in the design of the study; in the collection, analyses, or interpretation of data; in the writing of the manuscript, and in the decision to publish the results.

\section{References}

1. Baron, P.; Kocisko, M.; Dobransky, J.; Pollak, M.; Cmorej, T. Research and correlation of diagnostic methods for assessment of the state of oil filling in cycloid gearbox. Adv. Mater. Sci. Eng. 2015, 2015, 597841. [CrossRef]

2. Legutko, S. Development trends in machines operation maintenance. Eksploat. I Niezawodn. Maint. Reliab. 2009, 2, 8-16.

3. Baron, P.; Kocisko, M.; Dobransky, J.; Pollak, M.; Torokova, M. Research and application of methods of technical diagnostics for the verification of the design. Measurement 2016, 94, 245-253. [CrossRef]

4. Sorin-Dumitru, G.; Vasile, C. Industrial automation in the relative spiral feed and contact contour during cold orbital deformation. Int. Conf. Qual. Innov. Eng. Manag. 2012, 13, 367-370.

5. Olejarova, S.; Dobransky, J.; Svetlik, J.; Pituk, M. Measurements and evaluation of measurements of vibrations in steel milling process. Measurement 2017, 106, 18-25. [CrossRef]

6. Krolczyk, G.; Legutko, S.; Stoic, A. Influence of the cutting parameters and conditions onto surface hardness of duplex stainless steel after turning. Teh. Vjesn. Tech. Gaz. 2013, 20, 1077-1080.

7. Stejskal, T.; Svetlik, J.; Dovica, M.; Demec, P.; Kral, J. Measurement of static stiffness after motion on a three-axis CNC milling table. Appl. Sci. 2018, 8, 15. [CrossRef]

8. Pham, A.D.; Ahn, H.J. High precision reducers for industrial robots driving 4th industrial revolution: State of arts, analysis, design, performance evaluation and perspective. Int. J. Precis. Eng. Manuf.-Green Technol. 2018, 5, 519-533. [CrossRef]

9. Blagojevic, M.; Marjanovic, N.; Djordjevic, Z.; Stojanovic, B.; Disic, A. A new design of a two-stage cycloidal speed reducer. J. Mech. Des. 2011, 133, 085001. [CrossRef]

10. Litvin, F.L.; Feng, P.H. Computerized design and generation of cycloidal gearings. Mech. Mach. Theory 1996, 31, 891-911. [CrossRef]

11. Mao, H.; Liu, G.; Zeng, D.; Cao, Y.; He, K.; Du, R. A new design of cycloidal planetary reducer with internal cycloidal profile. ASME 2018 Int. Mech. Eng. Congr. Expo. 2018, 1-8. [CrossRef]

12. Sun, X.; Han, L.; Wang, J. Tooth modification and loaded tooth contact analysis of China bearing reducer. Proc. Inst. Mech. Eng. Part C J. Mech. Eng. Sci. 2019, 233, 6240-6261. [CrossRef]

13. Huang, Y.; Du, X.; Zhu, C.; Ni, G.; Ullah, N.; Liu, H. Mesh stiffness analysis of beveloid gears for the rotating vector transmission. J. Mech. Sci. Technol. 2019, 33, 3943-3953. [CrossRef]

14. Pham, A.D.; Ahn, H.J. Efficiency analysis of a cycloid reducer considering tolerance. J. Frict. Wear 2017, 38, 490-496. [CrossRef]

15. Terakawa, T.; Komori, M.; Morita, Y. Motion analysis and experiments of reducer-integrated motor using strain wave gearing system. In Proceedings of the ASME 2018 International Design Engineering Technical Conferences and Computers and Information in Engineering Conference, Quebec City, QC, Canada, 26-29 August 2018; pp. 1-6. [CrossRef]

16. Gorla, C.; Davoli, P.; Rosa, F.; Longoni, C.; Chiozzi, F.; Samarani, A. Theoretical and experimental analysis of a cycloidal speed reducer. J. Mech. Des. 2008, 130, 112604. [CrossRef]

17. Yamada, S.; Fujimoto, H. Precise joint torque control method for two-inertia system with backlash using load-side encoder. IEEJ J. Ind. Appl. 2019, 8, 75-83. [CrossRef]

18. Shih, Y.P.; Lo, S.H.; Sheen, B.T.; Tsai, Y.H. Precision evaluation for cycloidal gears. In Proceedings of the ASME 2019 International Design Engineering Technical Conferences and Computers and Information in Engineering Conference, Anaheim, CA, USA, 18-21 August 2019; pp. 1-5. [CrossRef]

19. Executive Summary World Robotics 2016 Industrial Robots. Available online: http://www.ifr.org/fileadmin/user_upload/ downloads/World_Robotics/2016/Executive_Summary_WR_Industrial_Robots_2016.pdf (accessed on 10 April 2020).

20. Xiong, Y.; Huang, K.; Xu, F.; Yi, Y.; Sang, M.; Zhai, H. Research on the influence of backlash on mesh stiffness and the nonlinear dynamics of spur gears. Appl. Sci. 2019, 9, 1029. [CrossRef]

21. Margielewicz, J.; Gaska, D.; Litak, G. Modelling of the gear backlash. Nonlinear Dyn. 2019, 97, 355-368. [CrossRef]

22. Getachew, A.A.; Hirpa, G.L. Effect of backlash on transmission error and time varying mesh stiffness. In International Workshop of Advanced Manufacturing and Automation; Springer: Singapore, 2021; Volume 737, pp. 18-28. [CrossRef]

23. Spitas, C.; Spitas, V. Coupled multi-DOF dynamic contact analysis model for the simulation of intermittent gear tooth contacts, impacts and rattling considering backlash and variable torque. J. Mech. Eng. Sci. 2016, 230, 1022-1047. [CrossRef]

24. Walha, L.; Fakhfakh, T.; Haddar, M. Nonlinear dynamics of a twostage gear system with mesh stiffness fluctuation, bearing flexibility and backlash. Mech. Mach. Theory 2009, 44, 1058-1069. [CrossRef] 
25. Xue, J.; Qiu, Z.; Fang, L.; Lu, Y.; Hu, W. Angular measurement of high precision reducer for industrial robot. IEEE Trans. Instrum. Meas. 2021, 70, 1-6. [CrossRef]

26. Caldarola, F.; Maiolo, M.; Solferino, V. A new approach to the Z-transform through infinite computation. Commun. Nonlinear Sci. Numer. Simul. 2020, 82, 105019. [CrossRef]

27. Farshidianfar, A.; Saghafi, A. Global bifurcation and chaos analysis in nonlinear vibration of spur gear systems. Nonlinear Dyn. 2014, 75, 783-806. [CrossRef]

28. Truxal, J.G. Control Engineers' Handbook: Servo-Mechanisms; McGraw-Hill: New York, NY, USA, $1958 ;$ p. 1112.

29. Xu, H.; Shi, Z.Y.; Yu, B.; Wang, H. Optimal measurement speed and its determination method in the transmission precision evaluation of precision reducers. Appl. Sci. 2019, 9, 2146. [CrossRef]

30. Hric, M.; Durovsky, F.; Fedak, V. Influence of non-linearities of cycloid gearbox. ATP J. 2012, 9, 42-44. 